\title{
Catalytic Enantioselective Borohydride Reduction of ortho-Fluorinated Benzophenones
}

\author{
Ai Kokura, Saiko Tanaka, Taketo Ikeno, and Tohru Yamada \\ Department of Chemistry, Faculty of Science and Technology, Keio \\ University, Hiyoshi, Kohoku-ku, Yokohama 223-8522, Japan \\ Email: yamadalchem.keio.ac.jp
}

Supporting Information

\section{General Procedures}

To a suspension of lithium borohydride $(16.34 \mathrm{mg}, 0.75 \mathrm{mmol})$ in $\mathrm{CHCl}_{3}$ $(3.0 \mathrm{~mL}), \mathrm{EtOH}(0.044 \mathrm{~mL}, 0.75 \mathrm{mmol})$ and tetrahydrofurfurylalcohol $(1.0 \mathrm{~mL}, 10.3 \mathrm{mmol})$ were added at $0{ }^{\circ} \mathrm{C}$ under $\mathrm{N}_{2}$, and the solution was stirred for 1 hour. Thus obtained pre-modified solution was added to a solution of $(R, R)$-cobalt catalyst $1 \mathrm{a}(2.9 \mathrm{mg}, 0.0050 \mathrm{mmol}, 1$

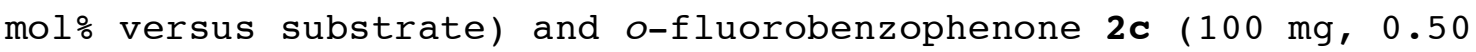
mmol) in $\mathrm{CHCl}_{3}(5.0 \mathrm{~mL})$ at $-20^{\circ} \mathrm{C}$ under $\mathrm{N}_{2}$, and the mixture was continued to stirr for 8 hours. The reaction was quenched by the addition of an aqueous phosphate buffer, and the solution was extracted with ethyl acetate twice. The combined organic layers were washed with brine and were dried over anhydrous sodium sulfate. Evaporation of the solvent in vacuo and purification by column chromatography on silica gel (hexane/ethyl acetate 8:1) gave the corresponding alcohol 3c as colorless oil (88\%, $88 \mathrm{mg})$.

${ }^{1} \mathrm{H}$ NMR and ${ }^{13} \mathrm{C}$ NMR spectra were measured on a JOEL model FX-270 or GX-400 spectrometer using $\mathrm{CDCl}_{3}$ as a solvent. HPLC analyses were performed with a Shimadzu LC-6A chromatograph using an optically active column (Daicel Chiralcel OD-H or Chiralpak AD-H or Chiralpak OB-H ). Optical rotations were measured with a JASCO DIP-370 digital polarimeter. Infrared spectra were recorded on a JASCO model IR-700 infrared spectrometer. EtOH and tetrahydrofurfurylalcohol were distilled over $\mathrm{CaH}_{2}$ before use. The optically active cobalt (II) complexes were prepared by the reported method.1,2) 


\section{p-Fluorobenzhydrol (3a)}

${ }^{1} \mathrm{H} \operatorname{NMR}\left(\mathrm{CDCl}_{3}\right): \delta=2.53(\mathrm{br} \mathrm{s}, 1 \mathrm{H}), 5.74(\mathrm{~s}, 1 \mathrm{H}), 6.93-7.01(\mathrm{~m}, 2 \mathrm{H})$, 7.20-7.32 (m, 7H). The ee value was determined by HPLC analysis (Chiralcel OB-H ; 25\% 2-propanol in hexane, flow $0.7 \mathrm{~mL} \mathrm{~min}^{-1}, 21.7$ $\min (R), 30.5 \min (S)) \cdot[\alpha]^{20}{ }_{\mathrm{D}}=+2.50^{\circ}\left(\mathrm{C} 0.879, \mathrm{CHCl}_{3}\right)\left(1 \mathrm{it} .{ }^{6}{ }^{6}[\alpha]^{24}\right.$ $=-7.1^{\circ}\left(\mathrm{C} 1.16, \mathrm{CHCl}_{3}\right),>99 \%$ ee $\left.(R)\right)$.

m-Fluorobenzhydrol $(3 b)$ :

${ }^{1} \mathrm{H} \operatorname{NMR}\left(\mathrm{CDCl}_{3}\right): \delta=2.96(\mathrm{br} \mathrm{s}, 1 \mathrm{H}), 5.71(\mathrm{~s}, 1 \mathrm{H}), 6.88-6.94(\mathrm{~m}, 1 \mathrm{H})$, $7.04-7.09(\mathrm{~m}, 2 \mathrm{H}), 7.19-7.30(\mathrm{~m}, 6 \mathrm{H}) \cdot[\alpha]_{\mathrm{D}}^{20}=-0.18^{\circ}\left(\mathrm{c} 0.887, \mathrm{CHCl}_{3}\right)$ $\left(1\right.$ it. $\left.{ }^{6}\right)[\alpha]_{\mathrm{D}}^{22}=-30.3^{\circ}\left(\mathrm{C} 1.00, \mathrm{CHCl}_{3}\right)$, >99\% ee $\left.(R)\right)$.

o-Fluorobenzhydrol (3c)

${ }^{1} \mathrm{H} \operatorname{NMR}\left(\mathrm{CDCl}_{3}\right): \delta=2.56(\mathrm{br} \mathrm{s}, 1 \mathrm{H}), 5.96(\mathrm{~s}, 1 \mathrm{H}), 6.84-6.98(\mathrm{~m}, 1 \mathrm{H})$, 7.00-7.04 $(\mathrm{m}, 1 \mathrm{H}), 7.07-7.24(\mathrm{~m}, 6 \mathrm{H}), 7.34-7.40(\mathrm{~m}, 1 \mathrm{H})$. The ee value was determined by HPLC analysis (Chiralcel OD-H ; 3\% 2-propanol in hexane, flow $\left.1.0 \mathrm{~mL} \mathrm{m^{-1 }}, 11.3 \mathrm{~min}(R), 12,7 \mathrm{~min}(S)\right) \cdot[\alpha]^{20}{ }_{\mathrm{D}}=-4.64^{\circ}$ ( C $\left.0.840, \mathrm{CHCl}_{3}\right)\left(\right.$ lit. ${ }^{3)}[\alpha]{ }_{\mathrm{D}}^{20}=+5.49^{\circ}\left(\mathrm{C} 0.906, \mathrm{CHCl}_{3}\right), 97 \%$ ee $\left.(S)\right)$. o-Chlorobenzhydrol (3d)

${ }^{1} \mathrm{H} \operatorname{NMR}\left(\mathrm{CDCl}_{3}\right): \delta=2.47(\mathrm{br} \mathrm{s}, 1 \mathrm{H}), 6.19(\mathrm{~s}, 1 \mathrm{H}), 7.18-7.38(\mathrm{~m}, 8 \mathrm{H})$, 7.57-7.61 $(\mathrm{m}, 1 \mathrm{H})$. The ee value was determined by HPLC analysis (Chiralcel OD-H ; 5\% 2-propanol in hexane, flow $1.0 \mathrm{~mL} \mathrm{~min}^{-1}, 17.6$ $\min (R), 21.7 \min (S)) \cdot[\alpha]_{\mathrm{D}}^{20}=-5.19^{\circ}\left(\mathrm{C} 0.976, \mathrm{CHCl}_{3}\right)\left(1 \mathrm{it} .{ }^{3)}[\alpha]_{\mathrm{D}}^{20}\right.$ $=-21.51\left(\mathrm{C} 1.136^{\circ}, \mathrm{CHCl}_{3}\right), 97 \%$ ee $\left.(S)\right)$.

\section{o-Bromobenzhydrol (3e)}

${ }^{1} \mathrm{H} \operatorname{NMR}\left(\mathrm{CDCl}_{3}\right): \delta=2.59(\mathrm{br} \mathrm{s}, 1 \mathrm{H}), 6.13(\mathrm{~s}, 1 \mathrm{H}), 7.08-7.14(\mathrm{~m}, 1 \mathrm{H})$, 7.1-7.37 $(\mathrm{m}, 6 \mathrm{H}), 7.49-7.56(\mathrm{~m}, 2 \mathrm{H})$. The ee value was determined by HPLC analysis (Chiralcel OD-H ; 3\% 2-propanol in hexane, flow 1.0 $\left.\mathrm{mL} \min ^{-1}, 25.1 \mathrm{~min}(R), 32.3 \mathrm{~min}(S)\right) \cdot[\alpha]_{\mathrm{D}}^{20}=-8.25^{\circ}\left(\mathrm{C} 1.089, \mathrm{CHCl}_{3}\right)$ $\left(\right.$ lit. ${ }^{3)}[\alpha]_{\mathrm{D}}^{22}=-41.9^{\circ}\left(\mathrm{C} 1.19, \mathrm{CHCl}_{3}\right), 96 \%$ ee $\left.(S)\right)$.

\section{o-Iodobenzhydrol (3f)}

${ }^{1} \mathrm{H} \operatorname{NMR}\left(\mathrm{CDCl}_{3}\right): \delta=2.75(\mathrm{br} \mathrm{s}, 1 \mathrm{H}), 5.97(\mathrm{~s}, 1 \mathrm{H}), 6.91-6.95(\mathrm{~m}, 1 \mathrm{H})$, 7.19-7.35 $(\mathrm{m}, 7 \mathrm{H}), 7.45-7.79(\mathrm{~m}, 1 \mathrm{H})$. The ee value was determined by HPLC analysis (Chiralcel OD-H ; 3\% 2-propanol in hexane, flow 1.0 $\left.\mathrm{mL} \min ^{-1}, 18.9 \min (R), 23.8 \mathrm{~min}(S)\right) \cdot[\alpha]^{20}{ }_{\mathrm{D}}=+4.45^{\circ}(\mathrm{C} 0.703$, acetone $)$ $\left(\right.$ lit. $\left.^{4}\right)[\mathrm{a}]_{\mathrm{D}}=+68.2^{\circ}(\mathrm{c} 1.5$, acetone $), 85 \%$ ee $\left.(R)\right)$.

\section{o-Hydroxybenzhydrol (3g)}

${ }^{1} \mathrm{H} \operatorname{NMR}\left(\mathrm{CDCl}_{3}\right): \delta=3.01(\mathrm{br} \mathrm{s}, 1 \mathrm{H}), 5.89(\mathrm{~s}, 1 \mathrm{H}), 6.71-6.81(\mathrm{~m}, 3 \mathrm{H})$, 
7.08-7.12 (m, 1H $), 7.22-7.29(\mathrm{~m}, 5 \mathrm{H}), 7.85(\mathrm{br} \mathrm{s}, 1 \mathrm{H})$. The ee value was determined by HPLC analysis (Chiralcel OD-H ; 10\% 2-propanol in hexane, flow $\left.1.0 \mathrm{~mL} \mathrm{~min}{ }^{-1}, 14.0 \mathrm{~min}, 22.5 \mathrm{~min}\right) .[\alpha]^{20}{ }_{\mathrm{D}}=-5.68^{\circ}$ ( $\mathrm{c} 0.827$, $\left.\mathrm{CH}_{3} \mathrm{CN}\right)\left(1\right.$ it. ${ }^{5)}[\alpha]_{\mathrm{D}}^{25}=-10.0^{\circ}\left(\mathrm{C} 1.04, \mathrm{CH}_{3} \mathrm{CN}\right), 99 \%$ ee $)$.

o-Methylbenzhydrol (3h)

${ }^{1} \mathrm{H} \mathrm{NMR}\left(\mathrm{CDCl}_{3}\right): \delta=2.21(\mathrm{br} \mathrm{s}, 1 \mathrm{H}), 2.23(\mathrm{~s}, 3 \mathrm{H}), 5.97(\mathrm{~s}, 1 \mathrm{H}), 7.12-7.34$ $(\mathrm{m}, 8 \mathrm{H}), 7.50(\mathrm{~m}, 1 \mathrm{H})$. The ee value was determined by HPLC analysis (Chiralcel OD-H ; 10\% 2-propanol in hexane, flow $0.8 \mathrm{~mL} \mathrm{~min}^{-1}, 12.6$ $\min , 19.4 \mathrm{~min})$.

\section{$2,3,4,5,6$-Pentafluorobenzhydrol (5a)}

${ }^{1} \mathrm{H} \operatorname{NMR}\left(\mathrm{CDCl}_{3}\right): \delta=2.74($ br s, $1 \mathrm{H}), 6.24(\mathrm{~s}, 1 \mathrm{H}), 7.32-7.39(\mathrm{~m}, 5 \mathrm{H})$. The ee value was determined by HPLC analysis (Chiralcel OD-H ; $1 \%$

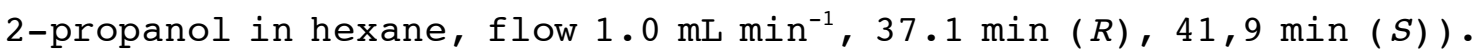
$[\alpha]_{\mathrm{D}}^{20}=+42.0^{\circ}\left(\mathrm{C} 1.224, \mathrm{CHCl}_{3}\right)\left(\right.$ lit. $\left.^{7}\right)[\alpha]=+31.0^{\circ}\left(\mathrm{C} 1.0, \mathrm{CHCl}_{3}\right)$, $70 \%$ ee $(R))$.

\section{2,6-Difluorobenzhydrol (5b)}

${ }^{1} \mathrm{H} \operatorname{NMR}\left(\mathrm{CDCl}_{3}\right): \delta=2.87(\mathrm{br} \mathrm{s}, 1 \mathrm{H}), 6.22(\mathrm{~s}, 1 \mathrm{H}), 6.85-6.91(\mathrm{~m}, 2 \mathrm{H})$, 7.19-7.39 $(\mathrm{m}, 6 \mathrm{H})$. The ee value was determined by HPLC analysis (Chiralcel OD-H ; 1\% EtOH in hexane, flow $0.5 \mathrm{~mL} \mathrm{~min}^{-1}, 43.9 \mathrm{~min}(S)$, $46.3 \min (R)) \cdot[\alpha]_{D}^{20}=+58.7^{\circ}\left(\mathrm{C} 1.041, \mathrm{CHCl}_{3}\right)\left(\right.$ lit. $\left.{ }^{6}\right)[\alpha]=-62.6^{\circ}$ (C $\left.1.30, \mathrm{CHCl}_{3}\right),>99 \%$ ee $(S)$ ).

2-Fluorophenyl-2'-naphthylmethanol (5c) :

${ }^{1} \mathrm{H} \operatorname{NMR}\left(\mathrm{CDCl}_{3}\right): \delta=2.47(\mathrm{br} \mathrm{s}, 1 \mathrm{H}), 6.30(\mathrm{~s}, 1 \mathrm{H}), 7.00-7.05(\mathrm{~m}, 1 \mathrm{H})$, $7.12-7.16(\mathrm{~m}, 1 \mathrm{H}), 7.23-7.27(\mathrm{~m}, 1 \mathrm{H}), 7.45-7.53(\mathrm{~m}, 4 \mathrm{H}), 7.78-7.83$ $(\mathrm{m}, 3 \mathrm{H}), 7.89(\mathrm{~s}, 1 \mathrm{H}) \cdot{ }^{13} \mathrm{C} \operatorname{NMR}\left(\mathrm{CDCl}_{3}\right): \delta=70.0(\mathrm{~d}, J=3.3 \mathrm{~Hz}), 115.3$ $(d, J=21.4 \mathrm{~Hz}), 124.2(\mathrm{~d}, J=3.3 \mathrm{~Hz}), 124.4,124.9,125.9,126.1,127.5$, $127.7(\mathrm{~d}, J=4.1 \mathrm{~Hz}), 128.0,128.2,129.1(\mathrm{~d}, J=8.3 \mathrm{~Hz}), 130.7$ (d, $J=13.2 \mathrm{~Hz}), 132.8,133.1,139.9,159.7(\mathrm{~d}, J=245 \mathrm{~Hz})$. IR (neat) $=$ $3348,3057,1614,1585,1508,1487,1456,1225,1174,1030,822,756$, $654,478 \mathrm{~cm}^{-1}$. The ee value was determined by HPLC analysis (Chiralcel

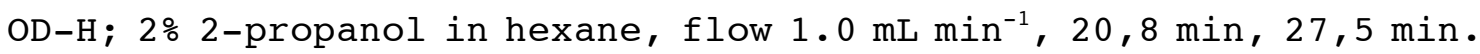
$[\alpha]_{D}^{20}=+17.3^{\circ}\left(\mathrm{C} 0.579, \mathrm{CHCl}_{3}\right)$. HRMS: m/z: calcd for $\mathrm{C}_{17} \mathrm{H}_{13} \mathrm{OF}:$ 252.0950 ; found : $252.0930\left[\mathrm{M}^{+}\right]$.

\section{2-Fluorophenyl-4'-methoxyphenylmethanol (5d) :}

${ }^{1} \mathrm{H} \mathrm{NMR}\left(\mathrm{CDCl}_{3}\right): \delta=3.26(\mathrm{br} \mathrm{s}, 1 \mathrm{H}), 3.67(\mathrm{~s}, 3 \mathrm{H}), 5.94(\mathrm{~s}, 1 \mathrm{H}), 6.76-6.78$ $(\mathrm{m}, 2 \mathrm{H}), 6.90-6.95(\mathrm{~m}, 1 \mathrm{H}), 7.05-7.21(\mathrm{~m}, 4 \mathrm{H}), 7.44-7.48(\mathrm{~m}, 1 \mathrm{H})$. 
${ }^{13} \mathrm{C} \operatorname{NMR}\left(\mathrm{CDCl}_{3}\right): \delta=55.0,69.3(\mathrm{~d}, J=3.3 \mathrm{~Hz}), 113.6,115.0(\mathrm{~d}, J=21.5$ $\mathrm{Hz}), 124.0(\mathrm{~d}, J=4.1 \mathrm{~Hz}), 127.2(\mathrm{~d}, J=4.1 \mathrm{~Hz}), 127.5,128.6$ (d, J=8.2 $\mathrm{Hz}), 131.0(\mathrm{~d}, J=13.2 \mathrm{~Hz}), 134.9,158.7,159.4$ (d, J=244 Hz). IR (neat) $=3398,3003,2935,1612,1585,1511,1456,1250,1173,1032,827$, $758,623,580 \mathrm{~cm}^{-1}$. The ee value was determined by HPLC analysis (Chiralcel OD-H; 2\% 2-propanol in hexane, flow $1.0 \mathrm{~mL} \mathrm{~min}^{-1}, 28.2 \mathrm{~min}$, $31.4 \mathrm{~min} .[\alpha]^{20}{ }_{\mathrm{D}}=-17.0^{\circ}\left(\mathrm{C} 0.665, \mathrm{CHCl}_{3}\right)$. HRMS: $\mathrm{m} / \mathrm{z}: \operatorname{calcd}$ for $\mathrm{C}_{14} \mathrm{H}_{13} \mathrm{O}_{2} \mathrm{~F}$ : 232.0990 ; found : $232.0898\left[\mathrm{M}^{+}\right]$.

\section{2-Fluoro-4'-fluorophenylmethanol (5e) :}

${ }^{1} \mathrm{H} \operatorname{NMR}\left(\mathrm{CDCl}_{3}\right): \delta=2.63(\mathrm{br} \mathrm{s}, 1 \mathrm{H}), 5.95(\mathrm{~s}, 1 \mathrm{H}), 6.86-6.92(\mathrm{~m}, 3 \mathrm{H})$, 7.01-7.24 (m, 4H),7.33-7.37 (m, 1H). ${ }^{13} \mathrm{C} \mathrm{NMR}\left(\mathrm{CDCl}_{3}\right): \delta=69.3,115.2$ $(d, J=21.5 \mathrm{~Hz}), 115.3(\mathrm{~d}, J=21.5 \mathrm{~Hz}), 124.3(\mathrm{~d}, J=3.3 \mathrm{~Hz}), 127.3$ (d, $J=3.3 \mathrm{~Hz}), 128.0(\mathrm{~d}, J=8.3 \mathrm{~Hz}), 129.2(\mathrm{~d}, J=8.3 \mathrm{~Hz}), 130.7(\mathrm{~d}, J=13.2$ $\mathrm{Hz}), 138.4(\mathrm{~d}, J=2.5 \mathrm{~Hz}), 159.6(\mathrm{~d}, J=244 \mathrm{~Hz}), 162.0(\mathrm{~d}, J=244 \mathrm{~Hz})$. $\operatorname{IR}($ neat $)=3348,1604,1508,1456,1225,1157,1103,1030,831,758$, $571,511 \mathrm{~cm}^{-1}$. The ee value was determined by HPLC analysis (Chiralcel OD-H ; 2\% 2-propanol in hexane, flow $1.0 \mathrm{~mL} \mathrm{~min}{ }^{-1}, 14.5 \mathrm{~min}, 17.9 \mathrm{~min}$. $[\alpha]_{\mathrm{D}}^{20}=-3.16\left(\mathrm{C} 0.782, \mathrm{CHCl}_{3}\right)$. HRMS: $\mathrm{m} / \mathrm{z}: \mathrm{calcd}$ for $\mathrm{C}_{13} \mathrm{H}_{10} \mathrm{OF}_{2}$ : 220.0700 ; found : $220.0708\left[\mathrm{M}^{+}\right]$.

\section{2-Fluorophenyl-2'-methoxyphenylmethanol (5f):}

${ }^{1} \mathrm{H} \operatorname{NMR}\left(\mathrm{CDCl}_{3}\right): \delta=3.19(\mathrm{br} \mathrm{s}, 1 \mathrm{H}), 3.73(\mathrm{~s}, 3 \mathrm{H}), 6.25(\mathrm{~s}, 1 \mathrm{H})$, 6.77-6.95(m, 3H), 7.01-7.20 (m, 4H), 7.35-7.40 (m, 1H). ${ }^{13} \mathrm{C}$ NMR $\left(\mathrm{CDCl}_{3}\right): \delta=55.2(\mathrm{~m}, J=2.5 \mathrm{~Hz}), 66.0(t, J=4.1 \mathrm{~Hz}), 110.4,114.9$ $(d, J=21.4 \mathrm{~Hz}), 120.5,123.7(\mathrm{~d}, J=3.3 \mathrm{~Hz}), 127.3,128.1(\mathrm{~d}, J=4.2$ $\mathrm{Hz}), 128.7(\mathrm{~d}, J=8.2 \mathrm{~Hz}), 128.7,129.7(\mathrm{~d}, J=13.2 \mathrm{~Hz}), 130.4,156.4$, $159.9(\mathrm{~d}, J=245 \mathrm{~Hz})$. IR (neat) $=3415,2939,2839,1749,1587,1489$, $1242,1028,754 \mathrm{~cm}^{-1}$. The ee value was determined by HPLC analysis (Chiralcel OD-H; 3\% 2-propanol in hexane, flow $1.0 \mathrm{~mL} \mathrm{~min}{ }^{-1}, 15.5 \mathrm{~min}$, $18.4 \min .[\alpha]_{D}^{20}=-11.21$ ( 0.558 , acetone). HRMS: $\mathrm{m} / \mathrm{z}:$ calcd for $\mathrm{C}_{14} \mathrm{H}_{13} \mathrm{O}_{2} \mathrm{~F}$ : 232.0990 ; found : $232.0874\left[\mathrm{M}^{+}\right]$.

\section{o-Fluoropheylethanol $(5 \mathrm{~h})$ :}

${ }^{1} \mathrm{H} \operatorname{NMR}\left(\mathrm{CDCl}_{3}\right): \delta=1.48(\mathrm{~d}, 3 \mathrm{H}, J=6.4 \mathrm{~Hz}), 2.40(\mathrm{br} \mathrm{s}, 1 \mathrm{H}), 5.16$ (q, $1 \mathrm{H}, J=6.4 \mathrm{~Hz}), 6.97-7.02(\mathrm{~m}, 1 \mathrm{H}), 7.11-7.14(\mathrm{~m}, 1 \mathrm{H}), 7.20-7.25(\mathrm{~m}$, $1 \mathrm{H}), 7.44-7.48(\mathrm{~m}, 1 \mathrm{H})$. The ee value was determined by HPLC analysis (Chiralcel $\mathrm{AD}-\mathrm{H} ; 1 \%$ ethanol in hexane, flow $1.0 \mathrm{~mL} \mathrm{~min} \mathrm{mi}^{-1}, 23.8 \mathrm{~min}$ $(R), 26.4 \mathrm{~min}(S) \cdot[\alpha]_{\mathrm{D}}^{20}=+40.1^{\circ}(\mathrm{C} 0.571, \mathrm{MeOH})\left(1 \mathrm{it} .{ }^{8}\right)[\alpha]_{\mathrm{D}}^{25}=-44.5^{\circ}$ 
(c $0.782, \mathrm{MeOH}),>99 \%$ ee $(S))$.

o-Fluorophenylpropanol (5i) :

${ }^{1} \mathrm{H} \operatorname{NMR}\left(\mathrm{CDCl}_{3}\right): \delta=0.94(t, 3 \mathrm{H}, J=7.6 \mathrm{~Hz}), 1.81(\mathrm{tq}, 2 \mathrm{H}, J=6.4,7.6$ $\mathrm{Hz}), 2.15$ (br $\mathrm{s}, 1 \mathrm{H}), 4.93(t, 1 \mathrm{H}, J=6.4 \mathrm{~Hz}), 6.99-7.03$ (m, $1 \mathrm{H})$, $7.12-7.16(\mathrm{~m}, 1 \mathrm{H}), 7.22-7.26(\mathrm{~m}, 1 \mathrm{H}), 7.43-7.46(\mathrm{~m}, 1 \mathrm{H})$. The ee value was determined by HPLC analysis (Chiralcel OD-H ; 1\% 2-propanol in hexane, flow $0.7 \mathrm{~mL} \mathrm{~min}^{-1}, 23.3 \mathrm{~min}, 25.2 \mathrm{~min} \cdot[\alpha]_{\mathrm{D}}^{20}=+32.6^{\circ}$ ( $\mathrm{C} 0.633$, $\left.\mathrm{CHCl}_{3}\right)\left(\right.$ lit. $\left.{ }^{9}\right)[\alpha]_{\mathrm{D}}^{25}=-20.1^{\circ}\left(\mathrm{C} 1.77, \mathrm{CHCl}_{3}\right), 62 \%$ ee $\left.(S)\right)$.

\section{References}

1) Yamada, T.; Nagata, T.; Ikeno, T.; Ohtsuka, Y.; Sagara, A.; Mukaiyama, T. Inorg. Chim. Acta 1999, 296, 86-93.

2) Ikeno, T.; Sato, M.;Sekino, H.; Nishizuka, A.; Yamada, T. Bull. Chem. Soc. Jpn. 2001, 74, 2139-2150.

3) Ohkuma, T.; Koizumi, M.; Ikehira, H.; Yokozawa, T.; Noyori, R. Org. Lett. 2000, 2, 659-662.

$4)$ Brown, E.; Leze, A.; Toet, J. Tetrahedron Asymmetry 1992, 3, 841-844.

5) Shieh, W-C.; Cantrell, W. R.; Carlson, Jr., J. A. Tetrahedron Lett. 1995, 36, 3797-3800.

6) Naito, J.; Kosaka, M.; Sugito, T.; Watanabe, M.; Harada, N.; Pirkle, W. H. Chirality 2004, 16, 22-35.

7) Yong, K. H.; Taylor, M. J.; Chong, J. M. Org. Lett. 2002, 4, 3553-3556.

8) Nakamura, K.; Matsuda, T. J. Org. Chem. 1998, 63, 8957-8964.

9) Seebach, D.; Beck, A. K.; Schmidt, B.; Wang, Y. M. Tetrahedron 1994, 50, 4363-4384. 


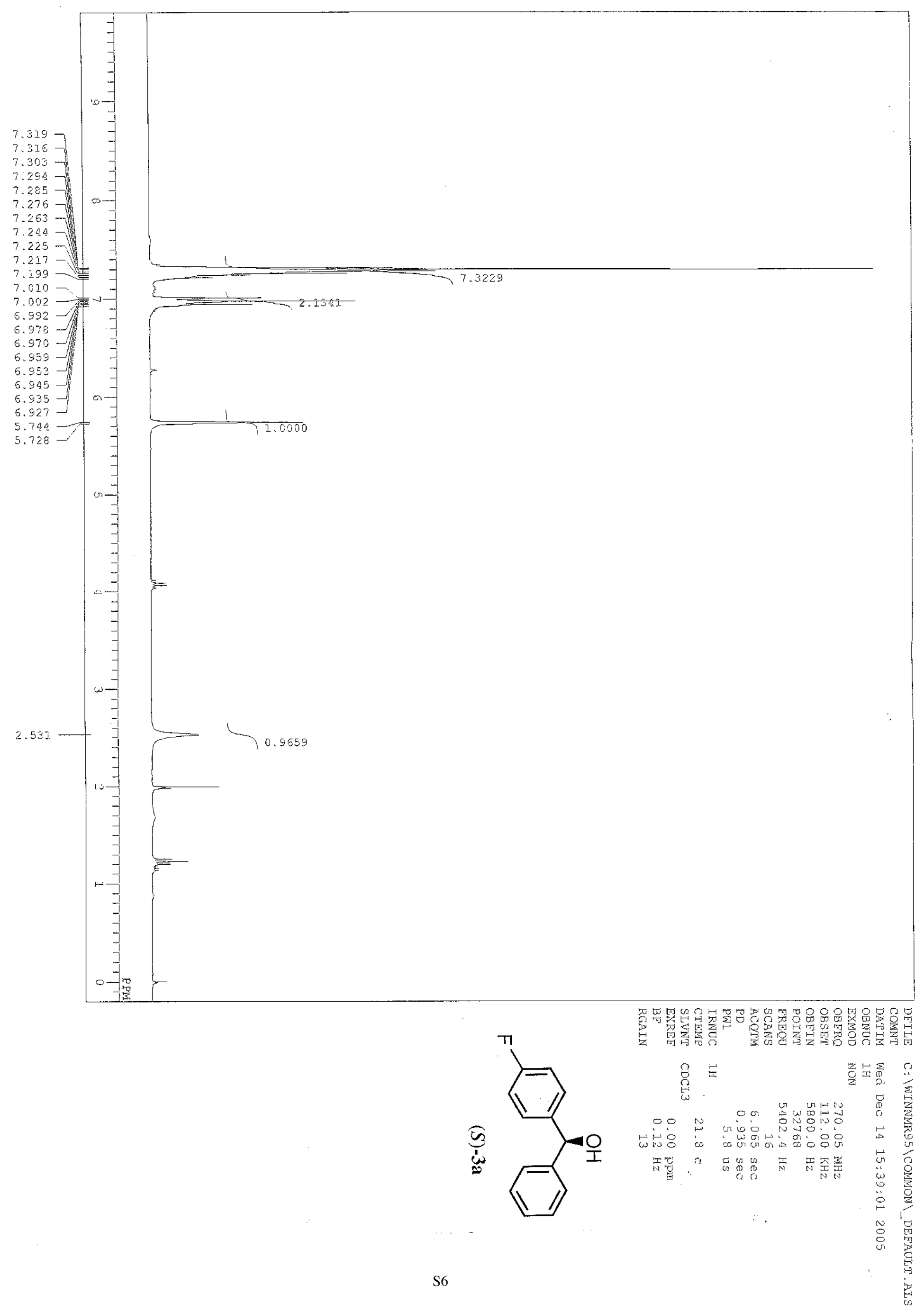




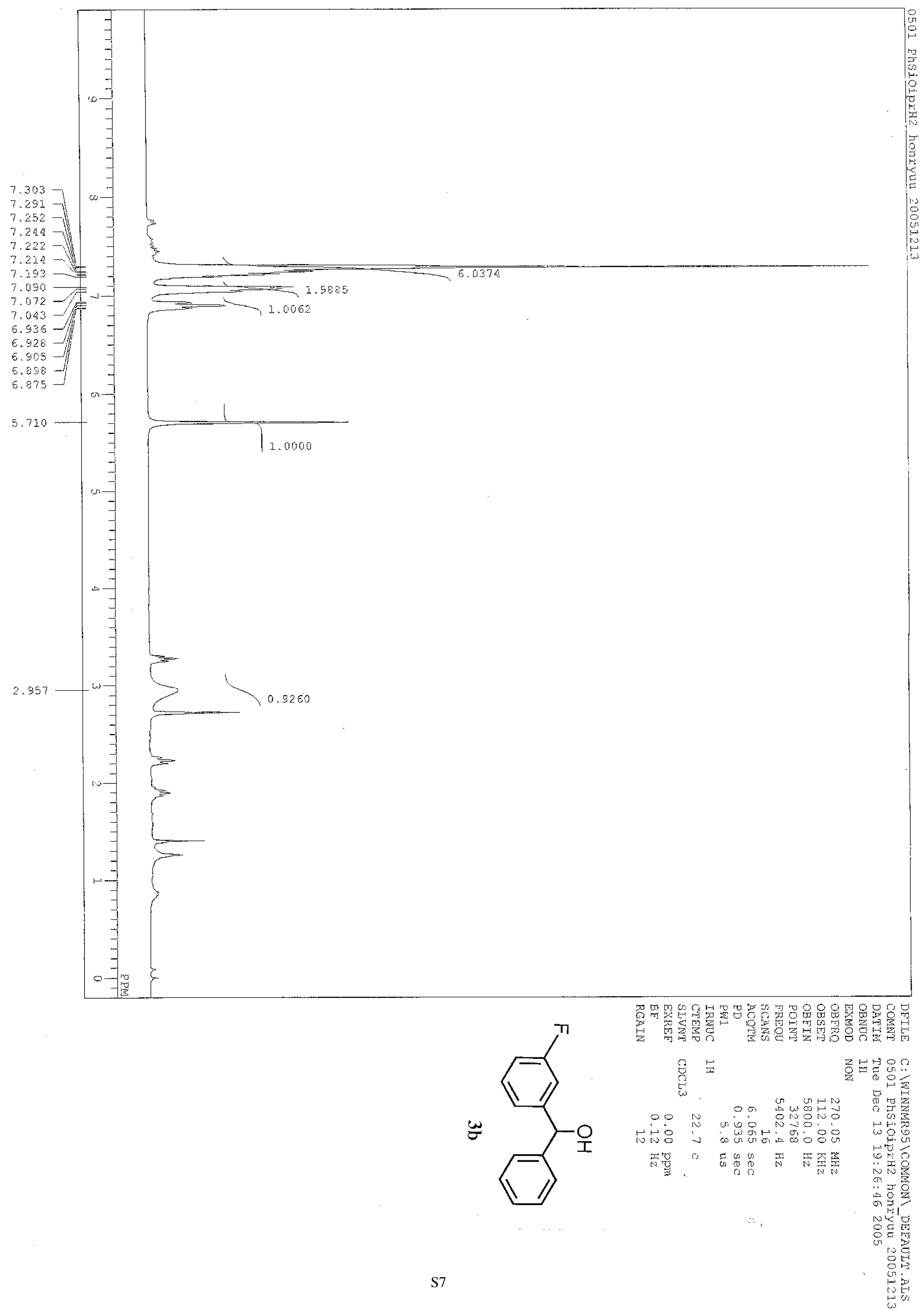



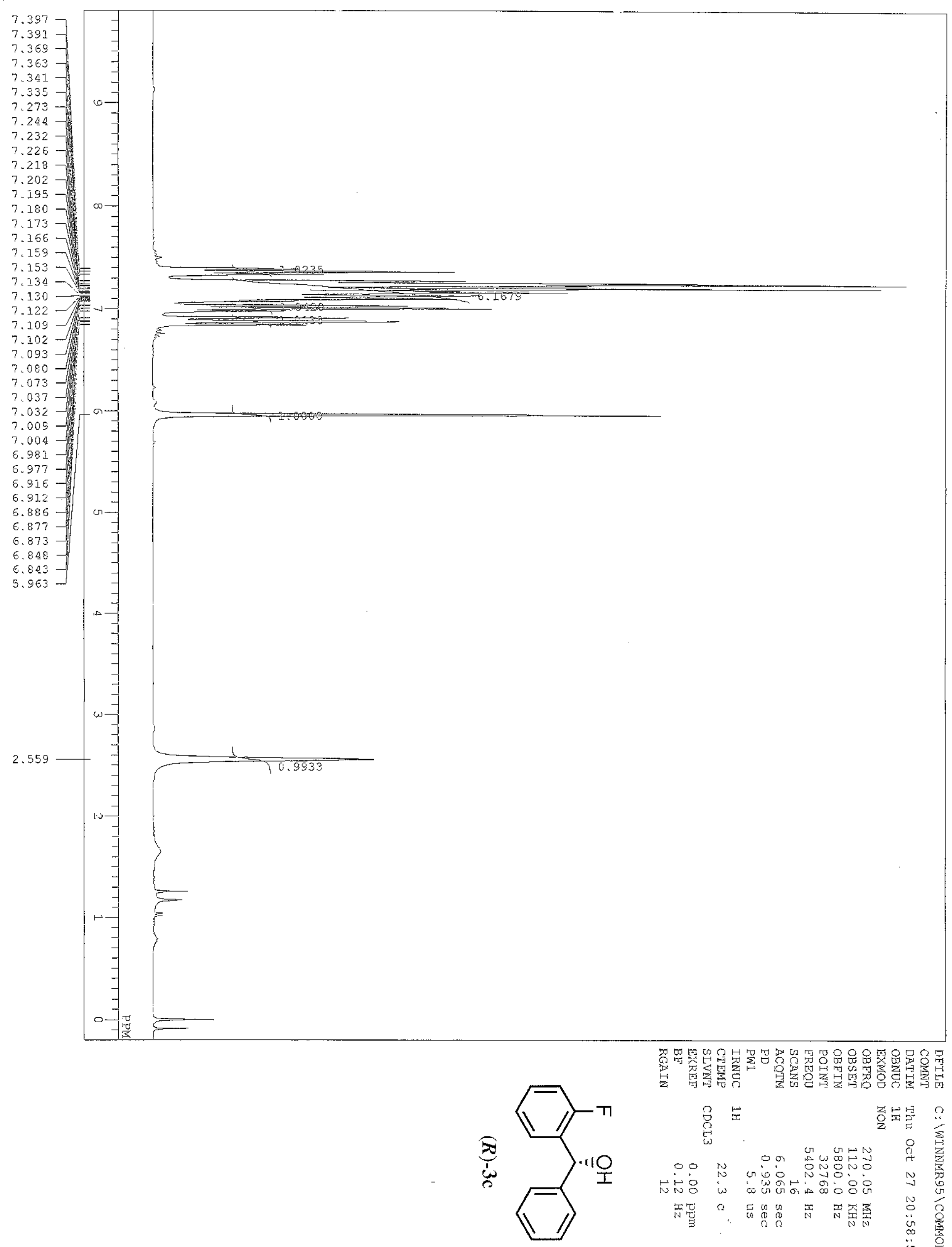

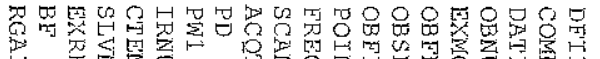

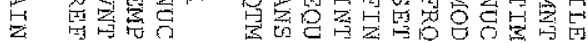

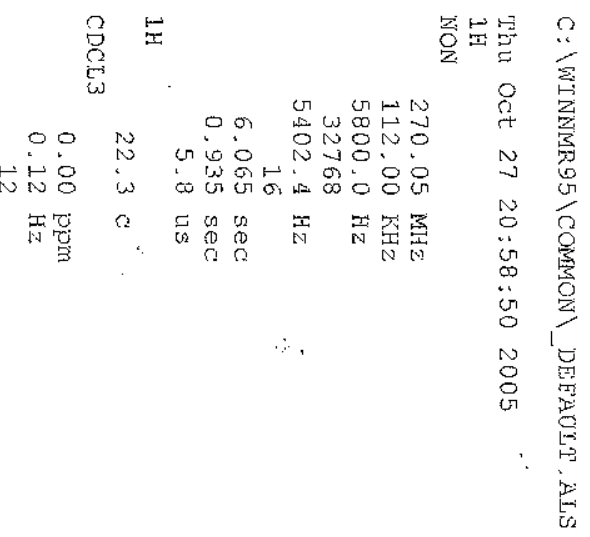




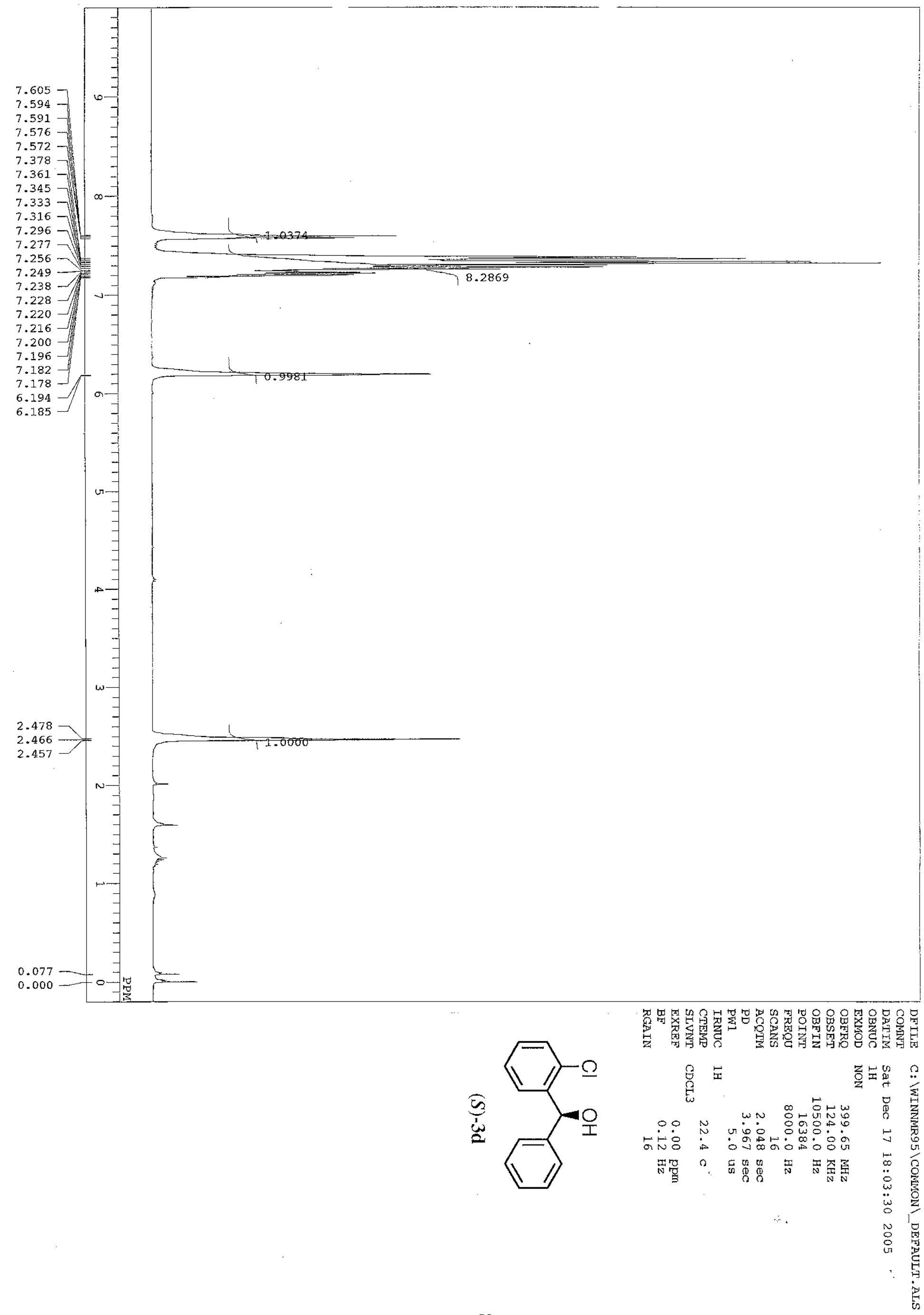



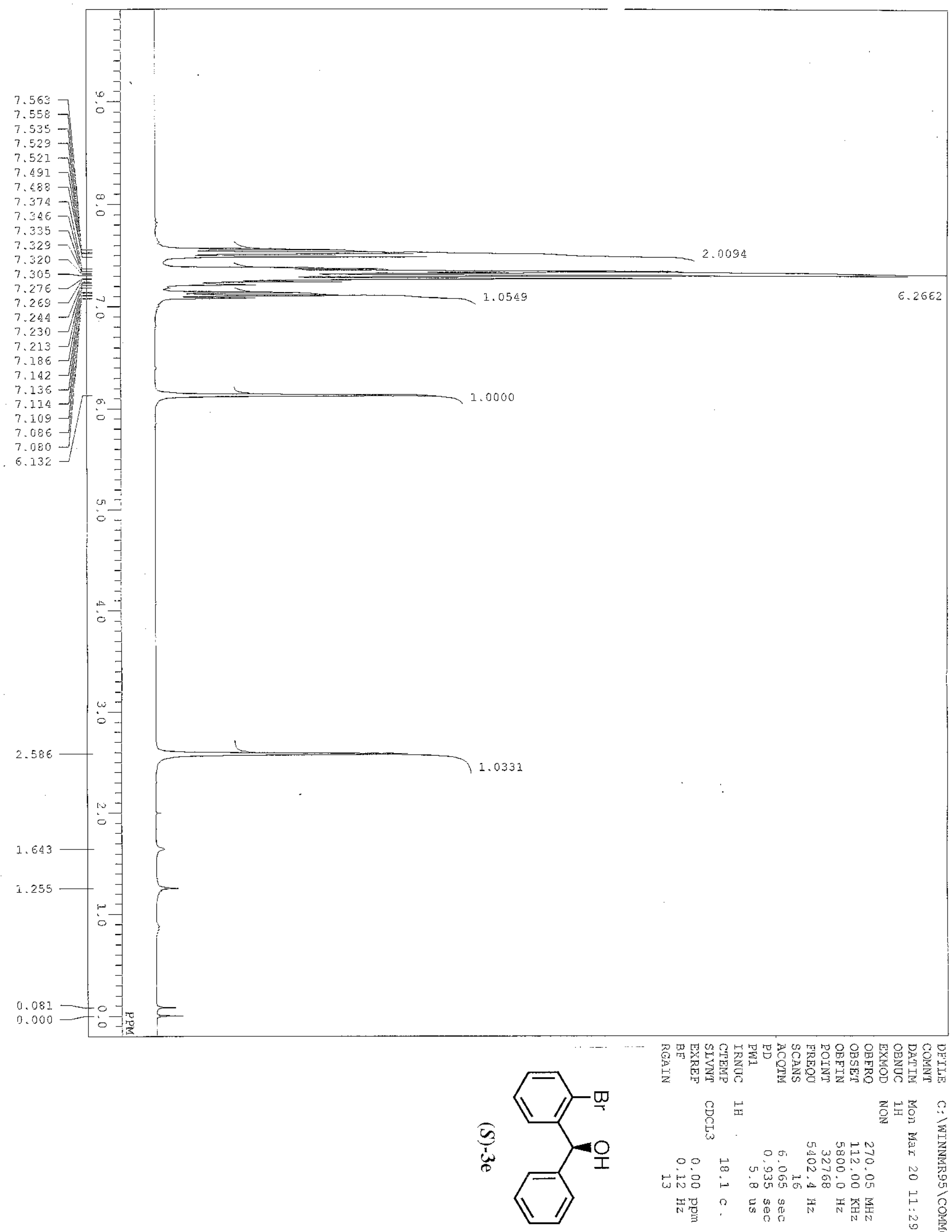

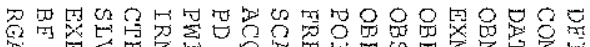

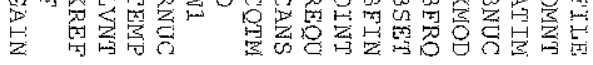

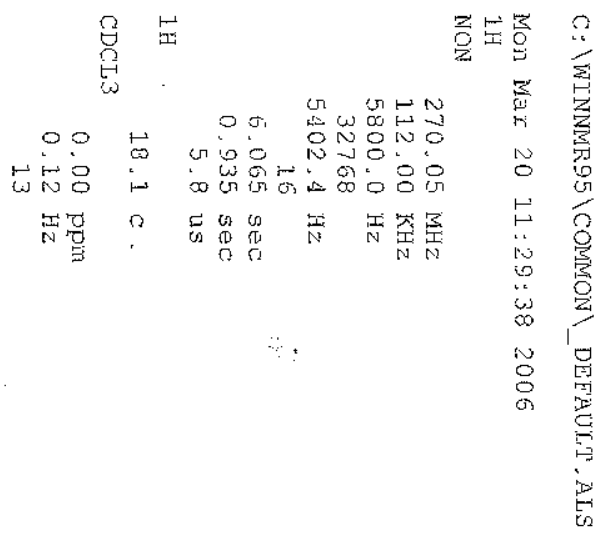



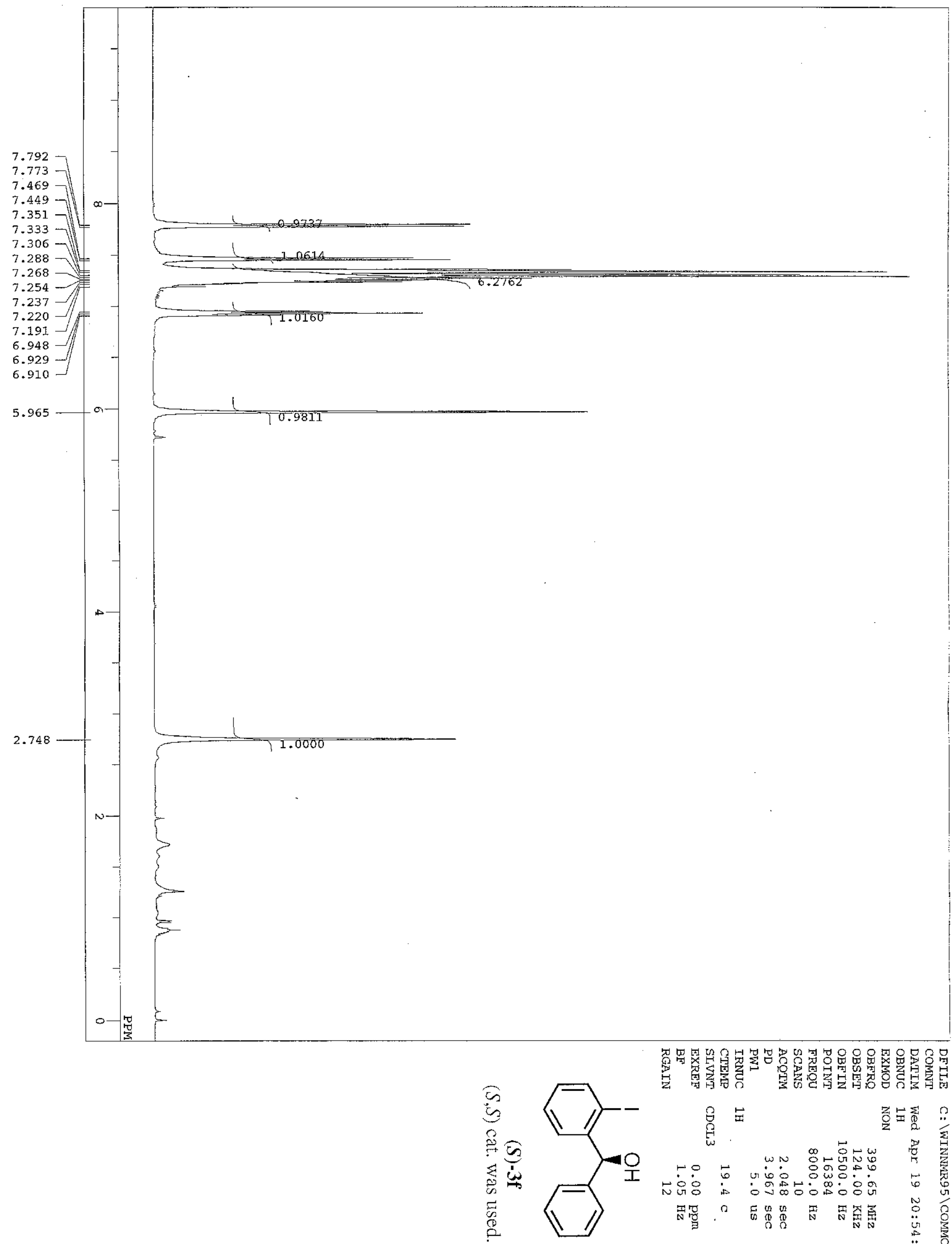

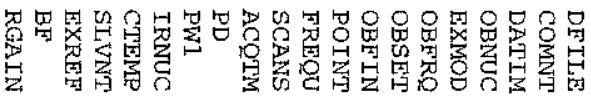

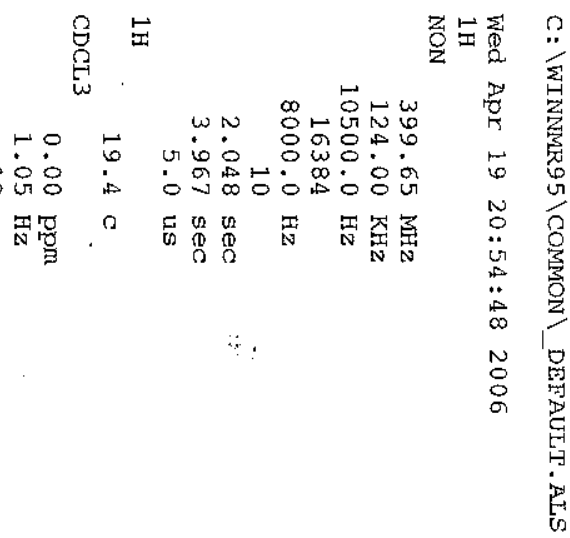



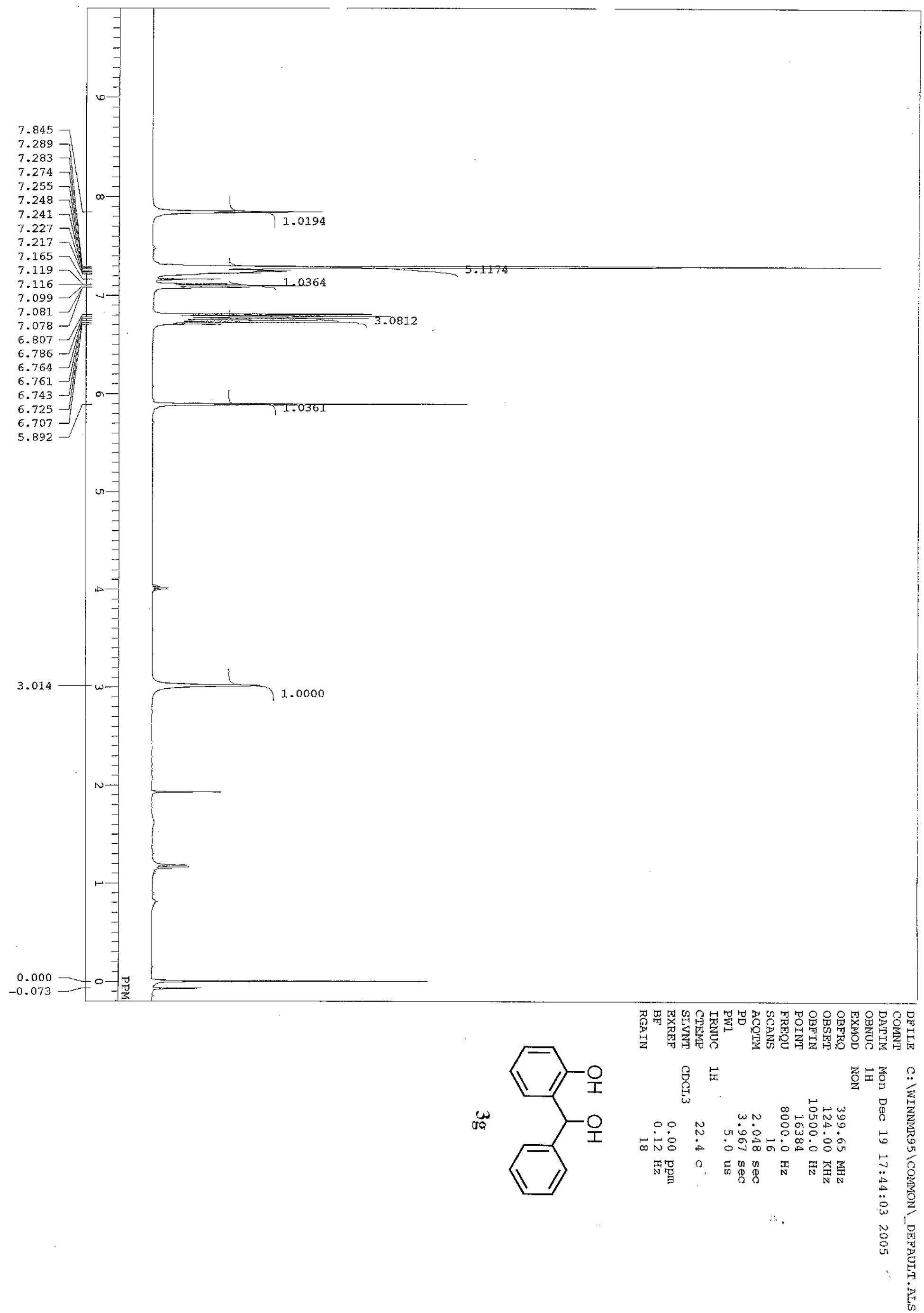


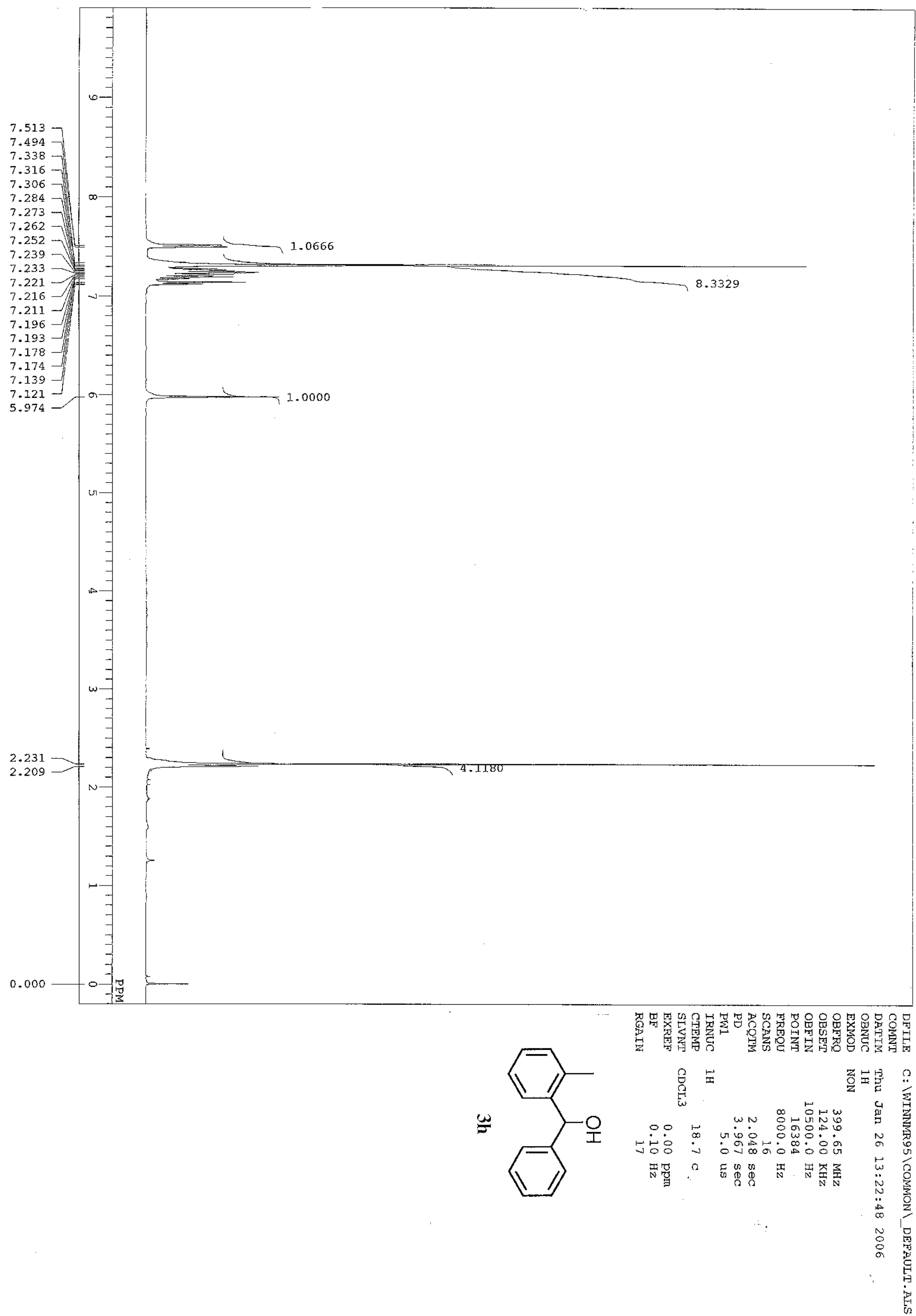




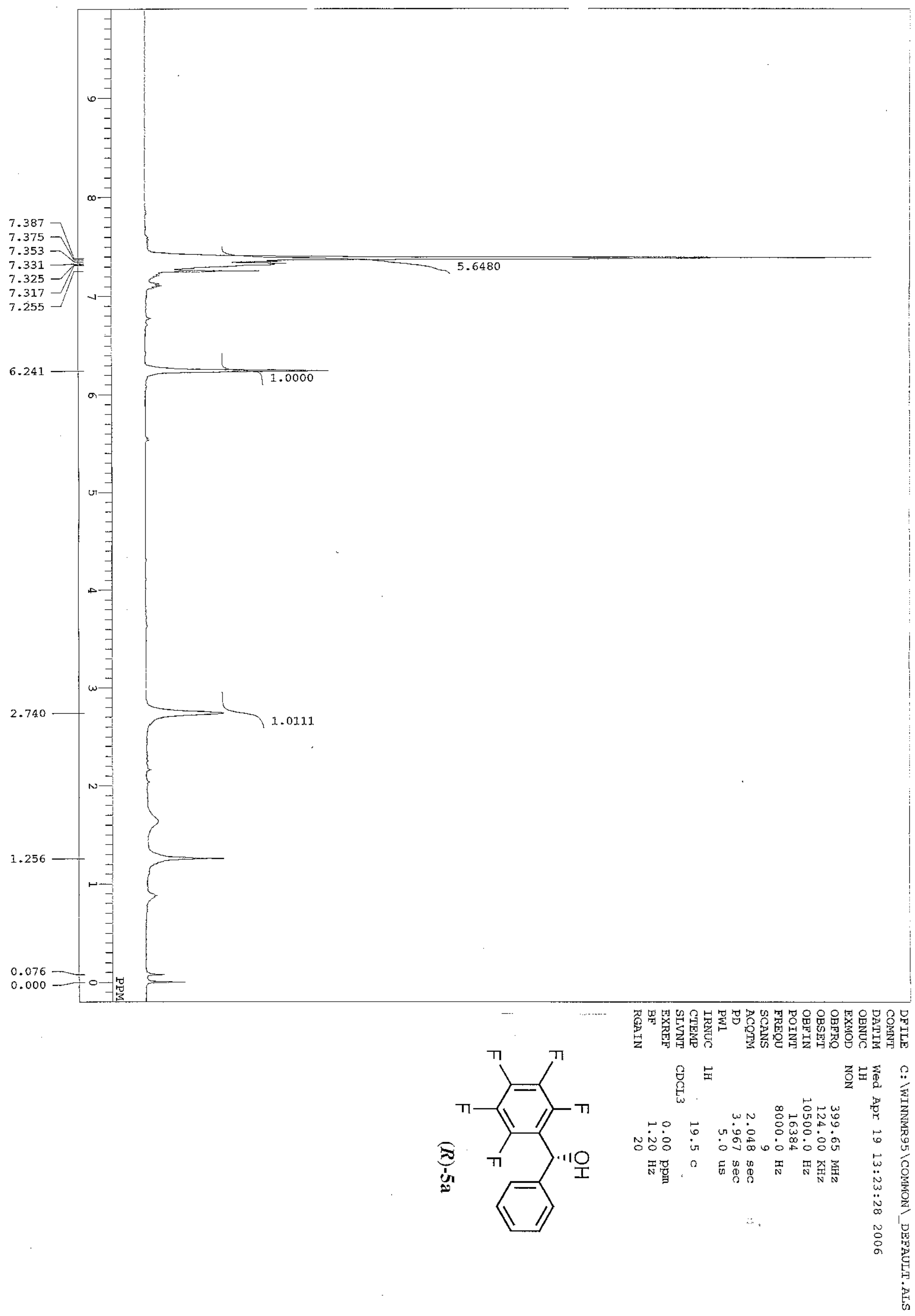




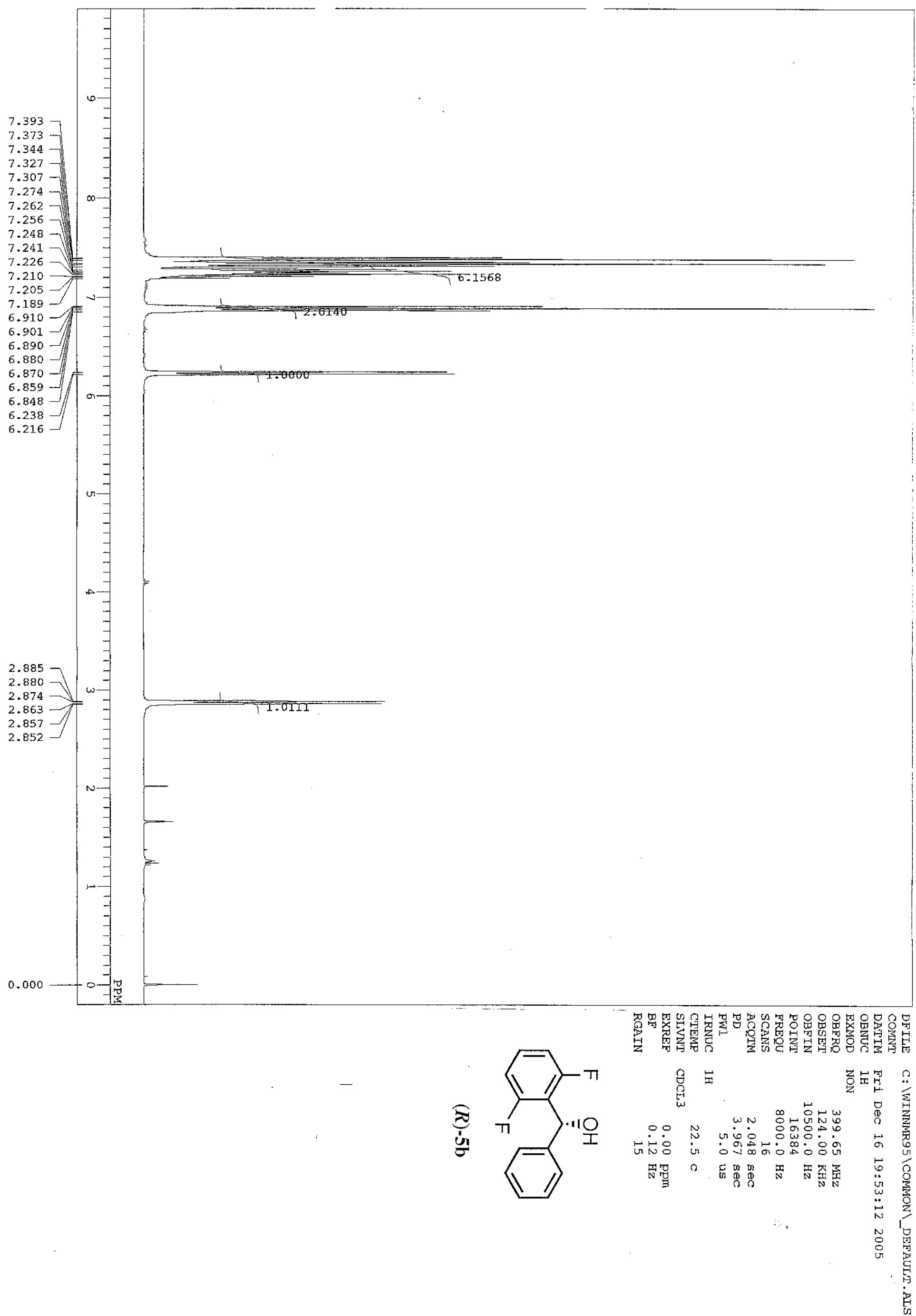




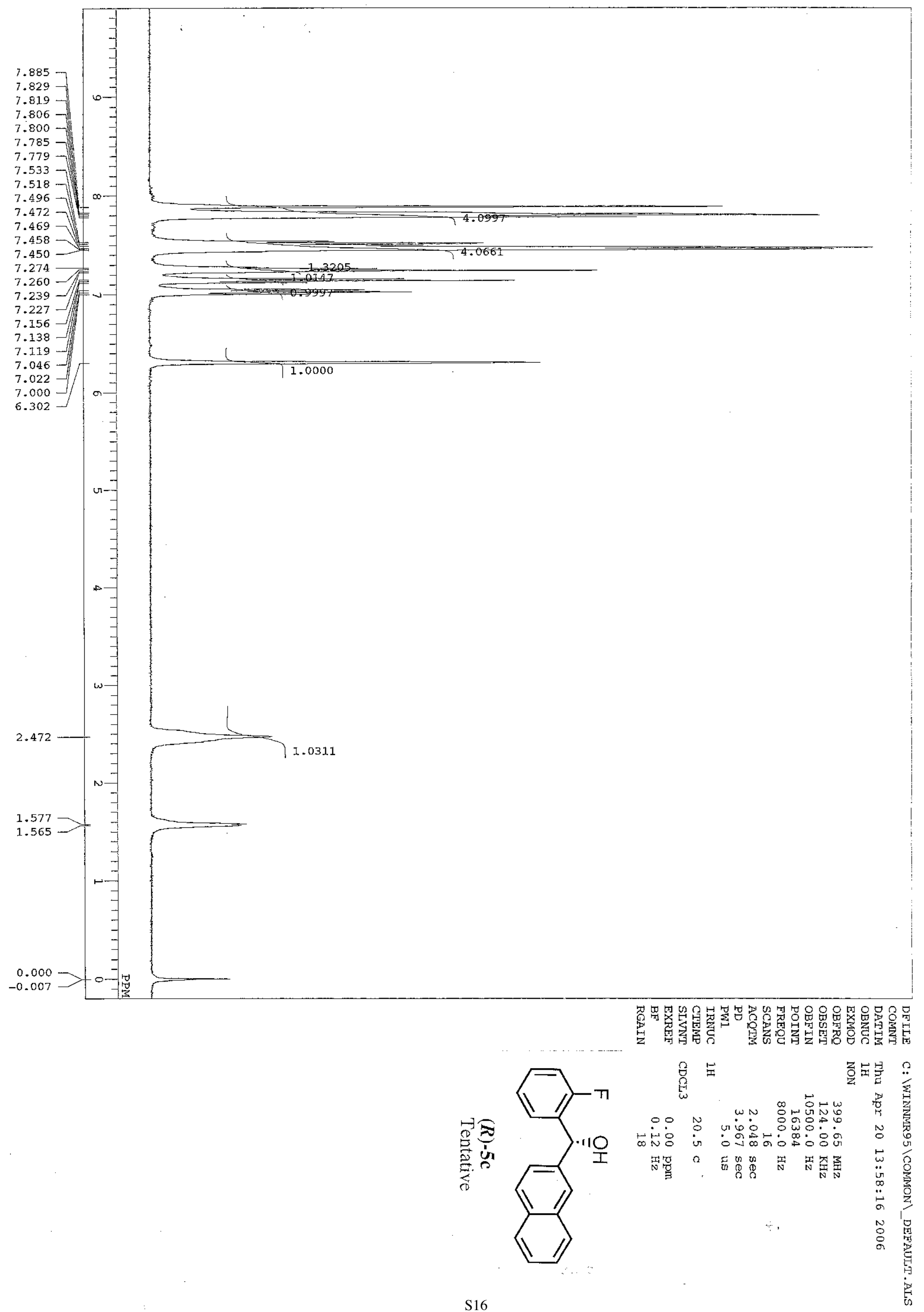




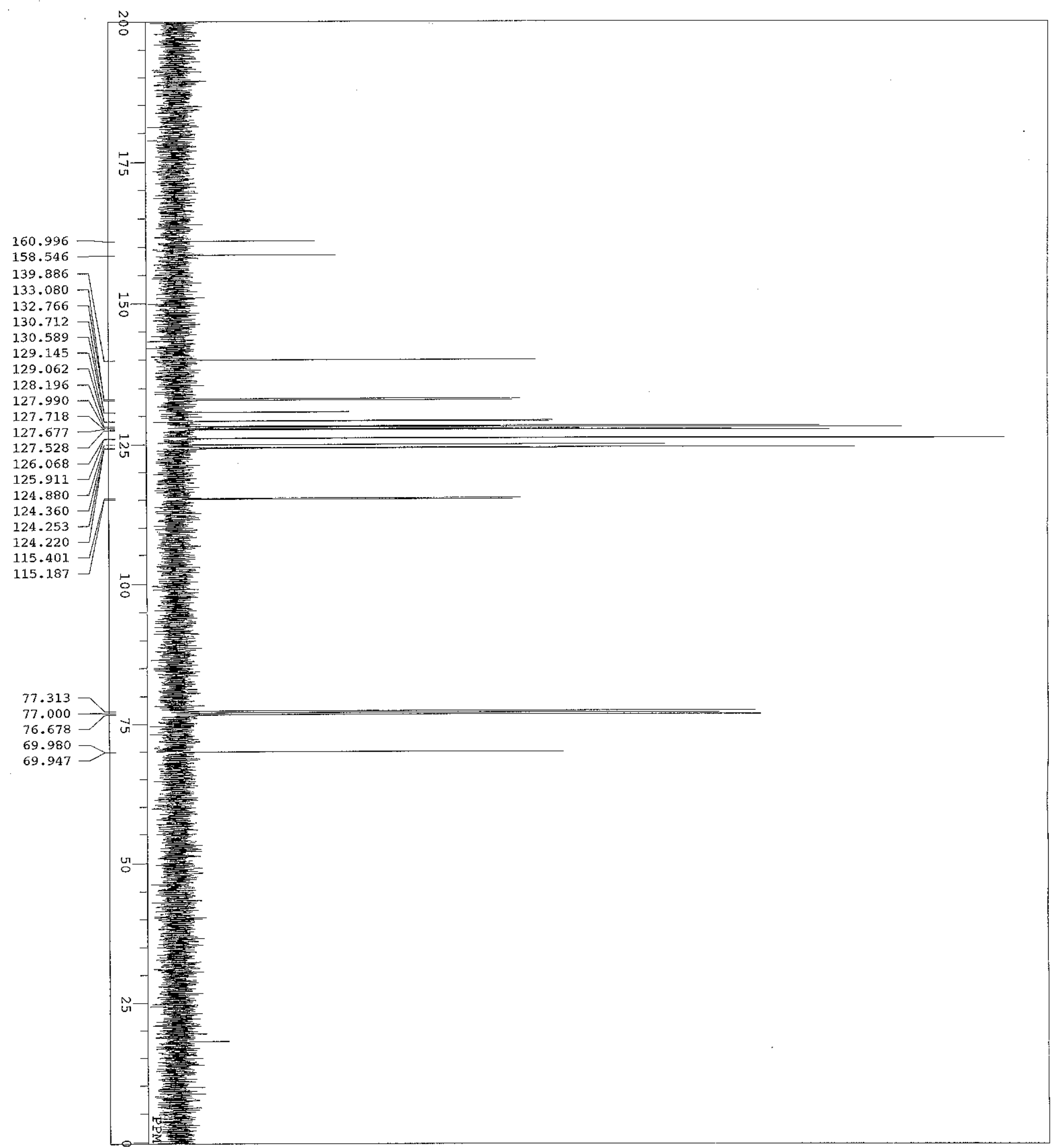

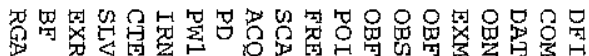

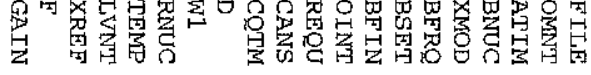

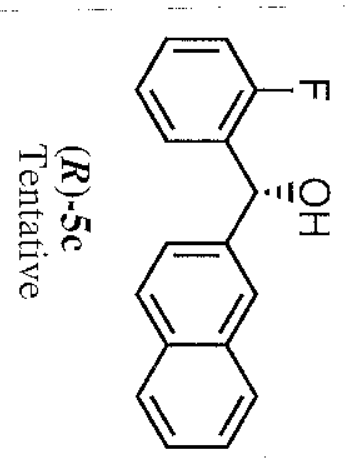

苗 品 塄颉最

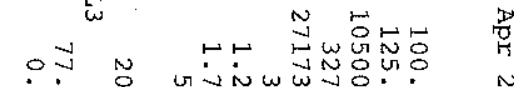
Ni⿱宀⿻三丨寸

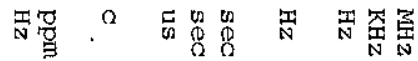




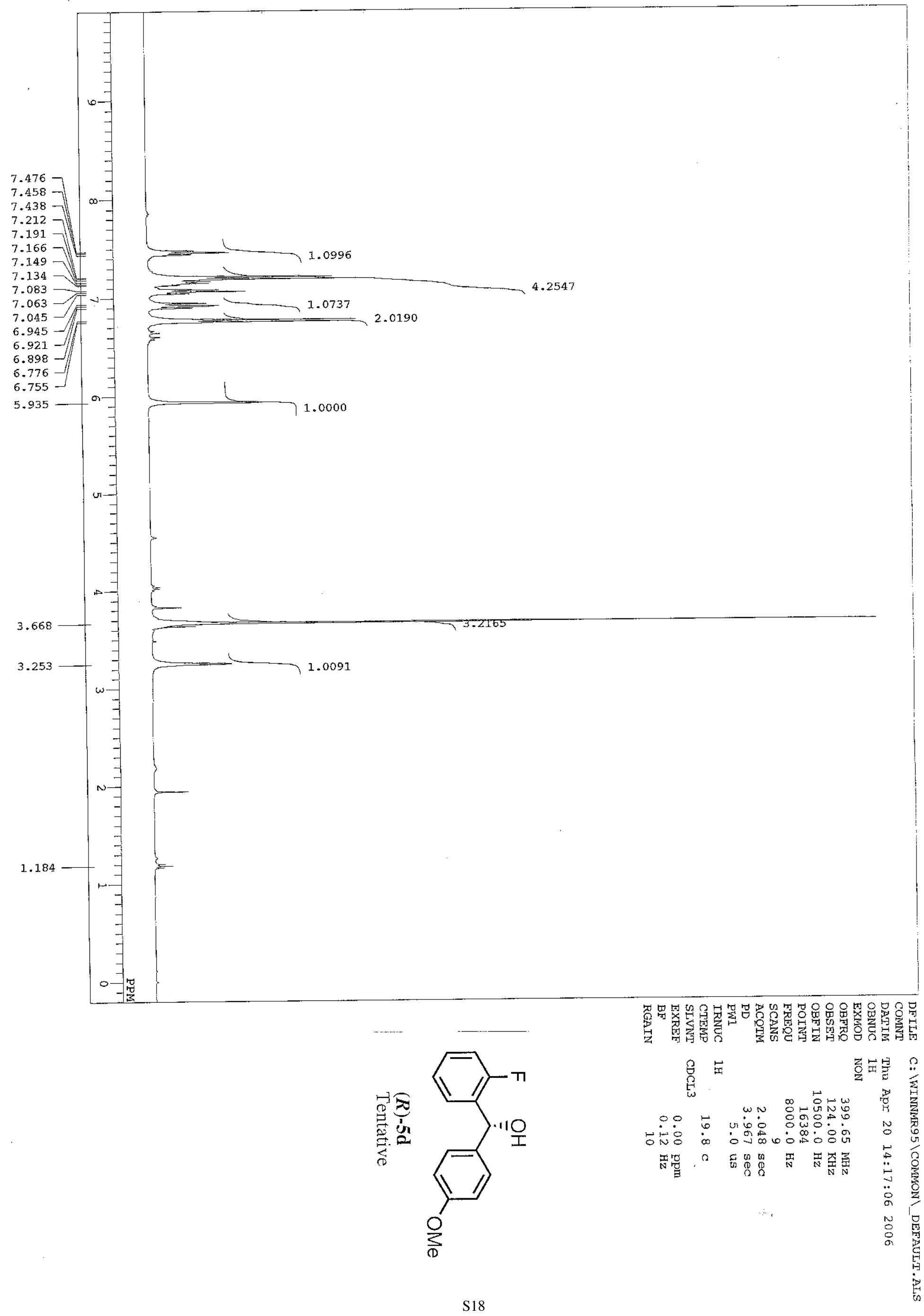




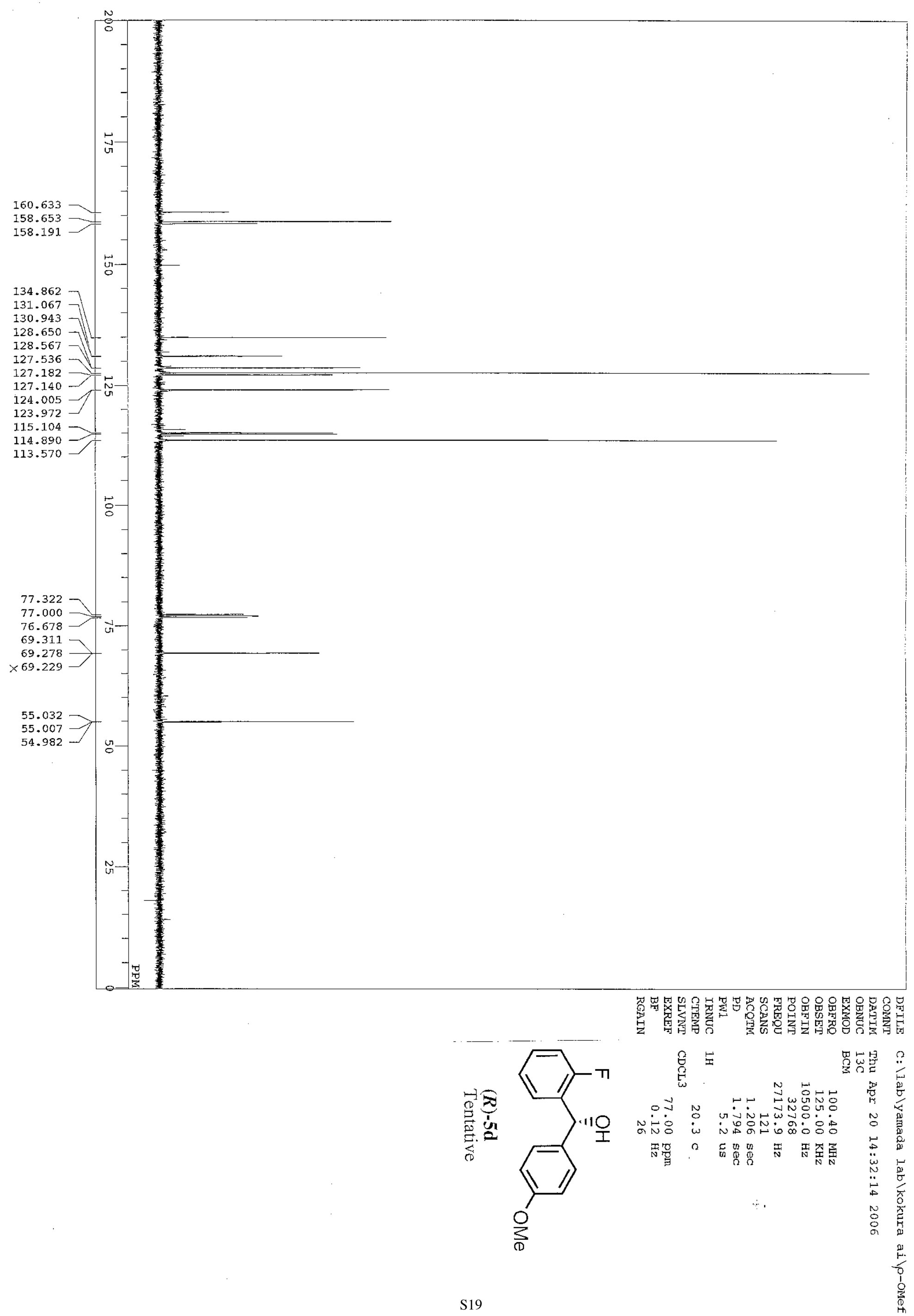



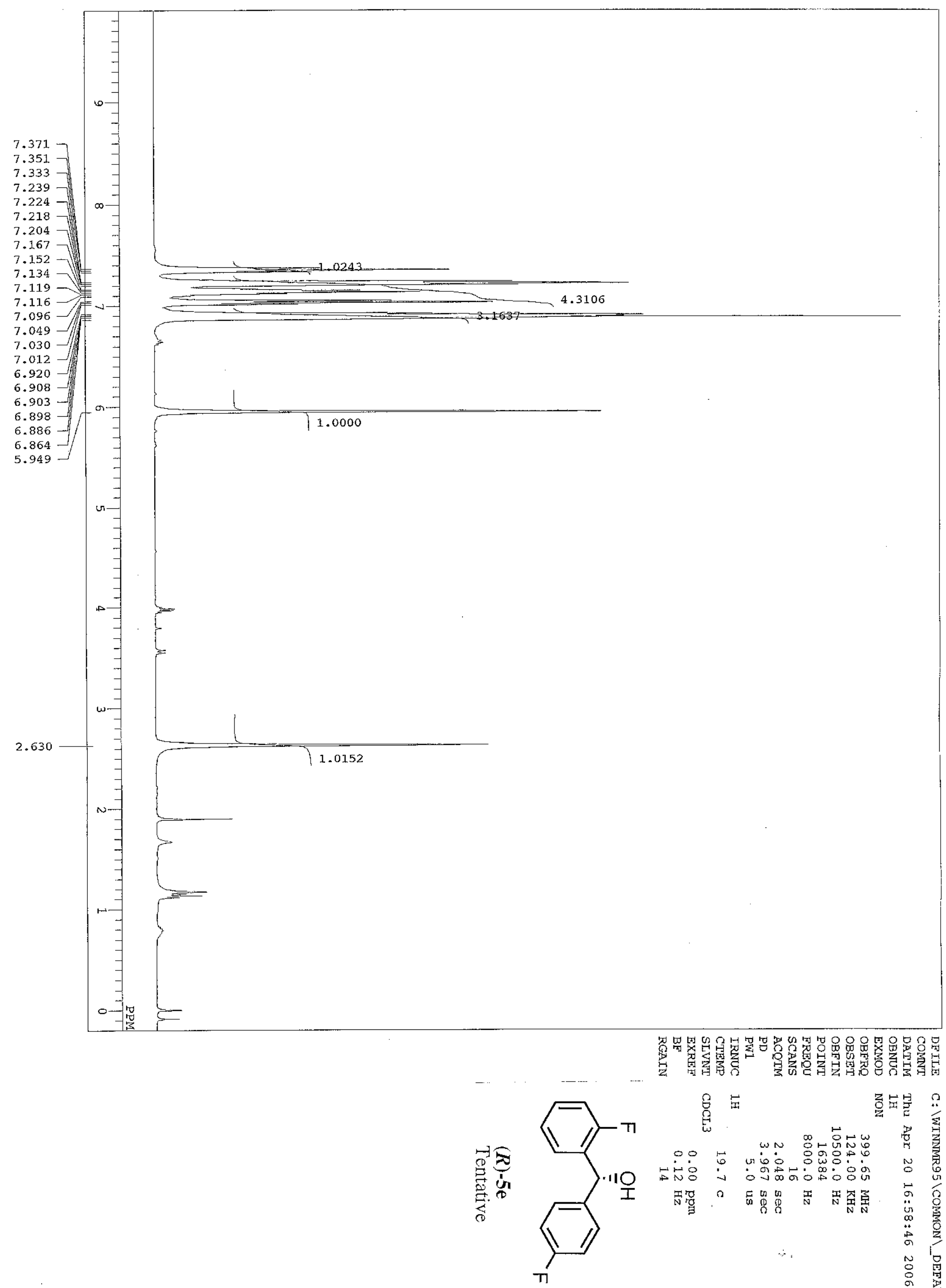

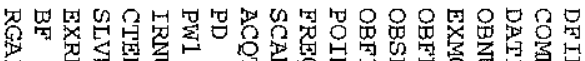

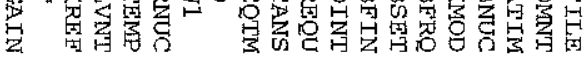

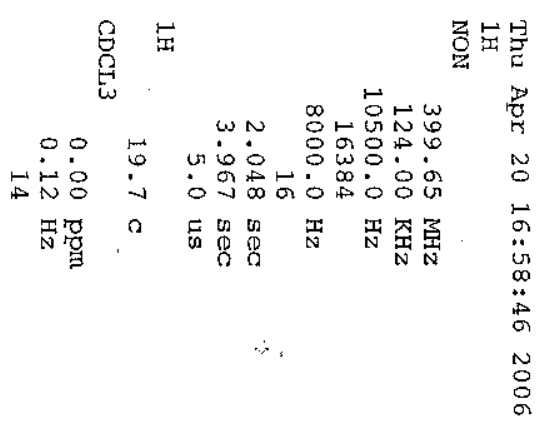




$$
1
$$




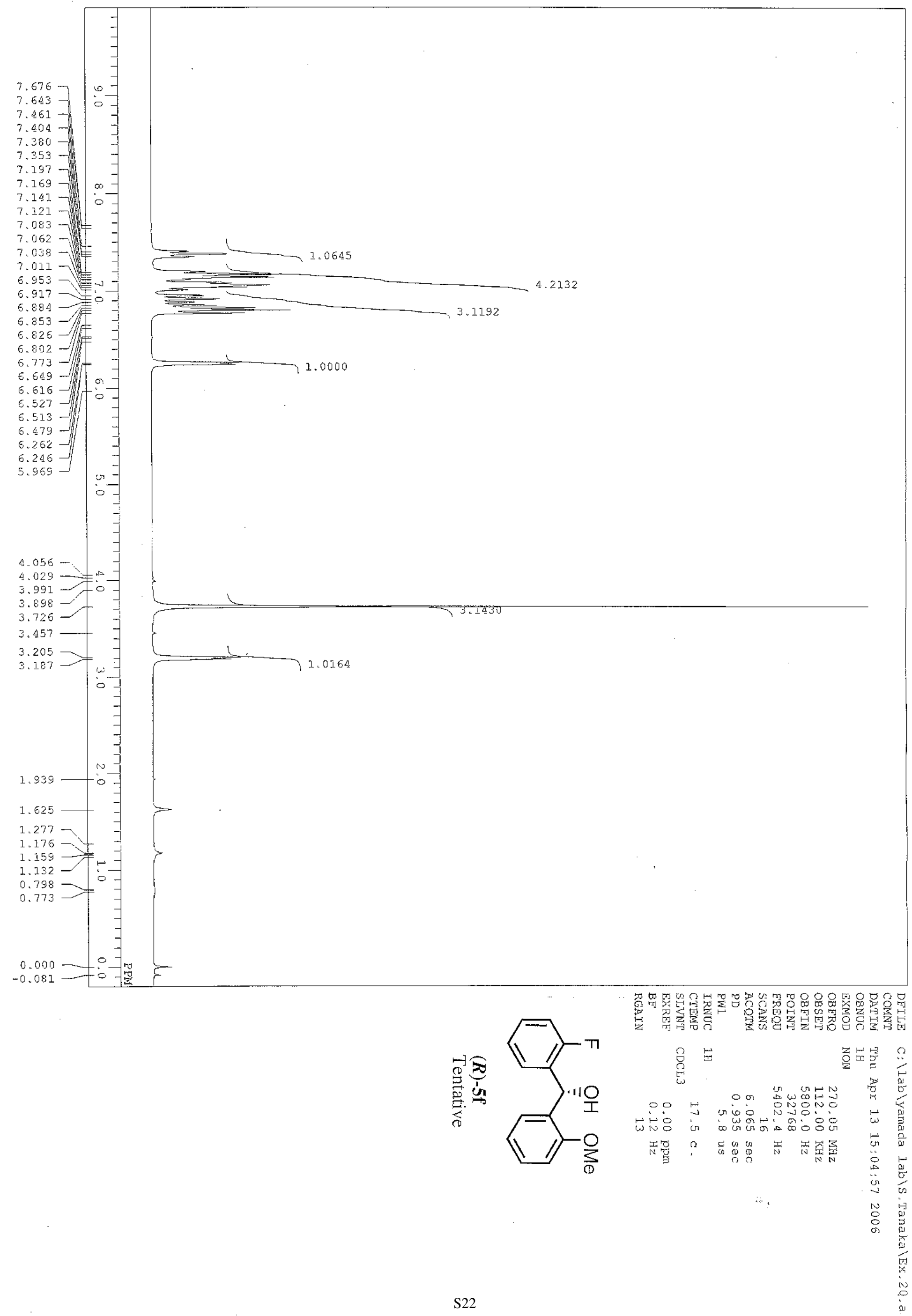




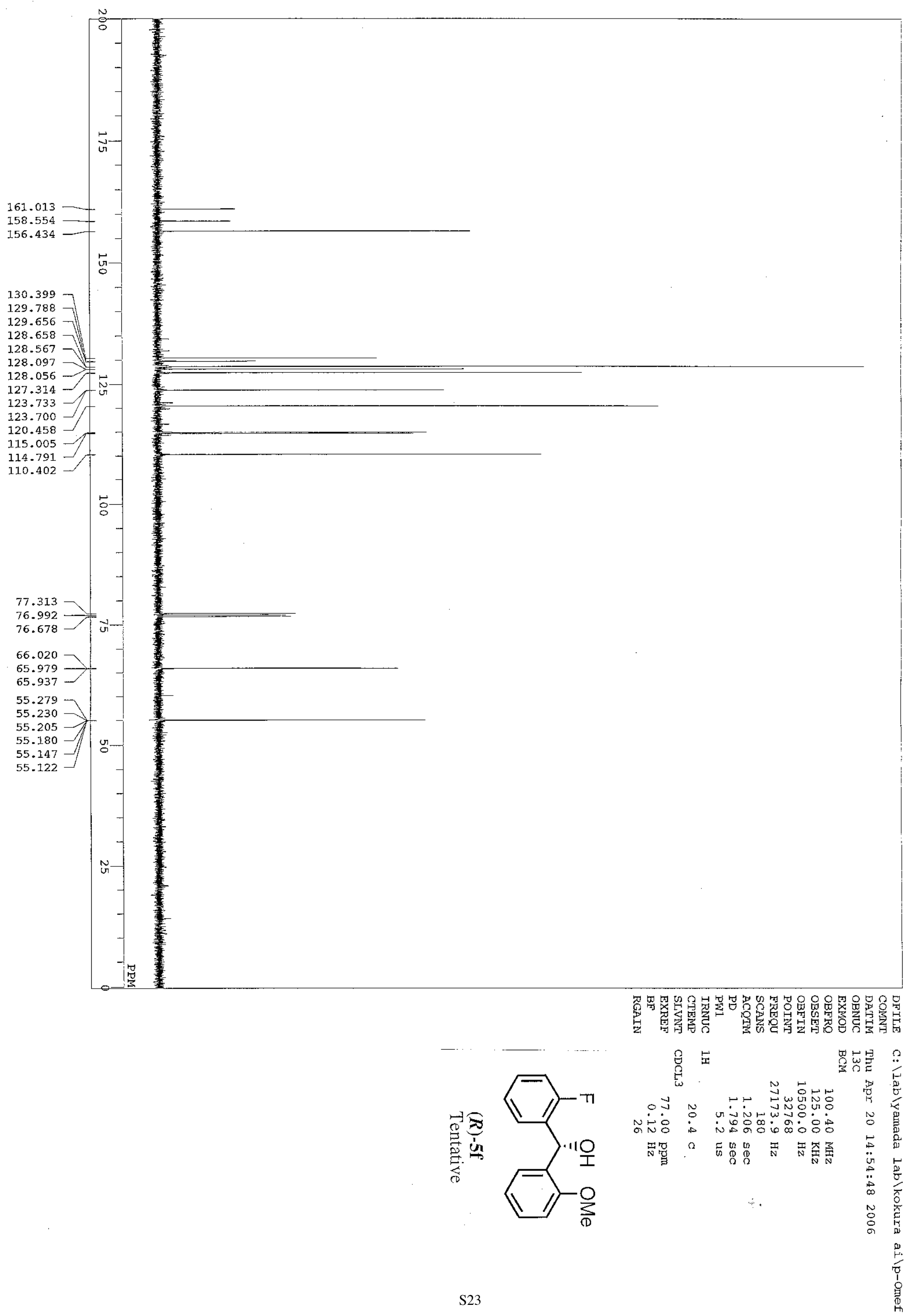




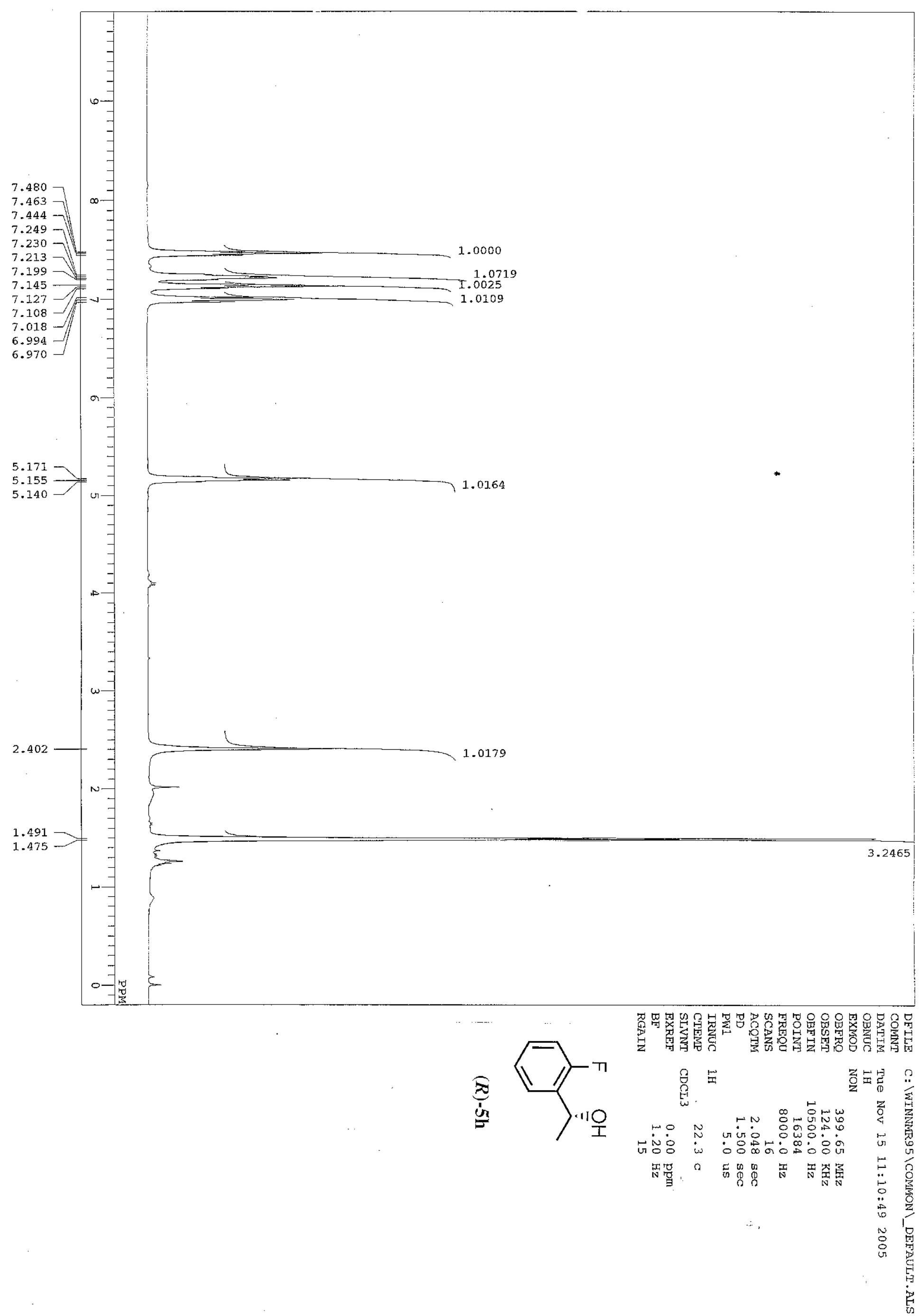




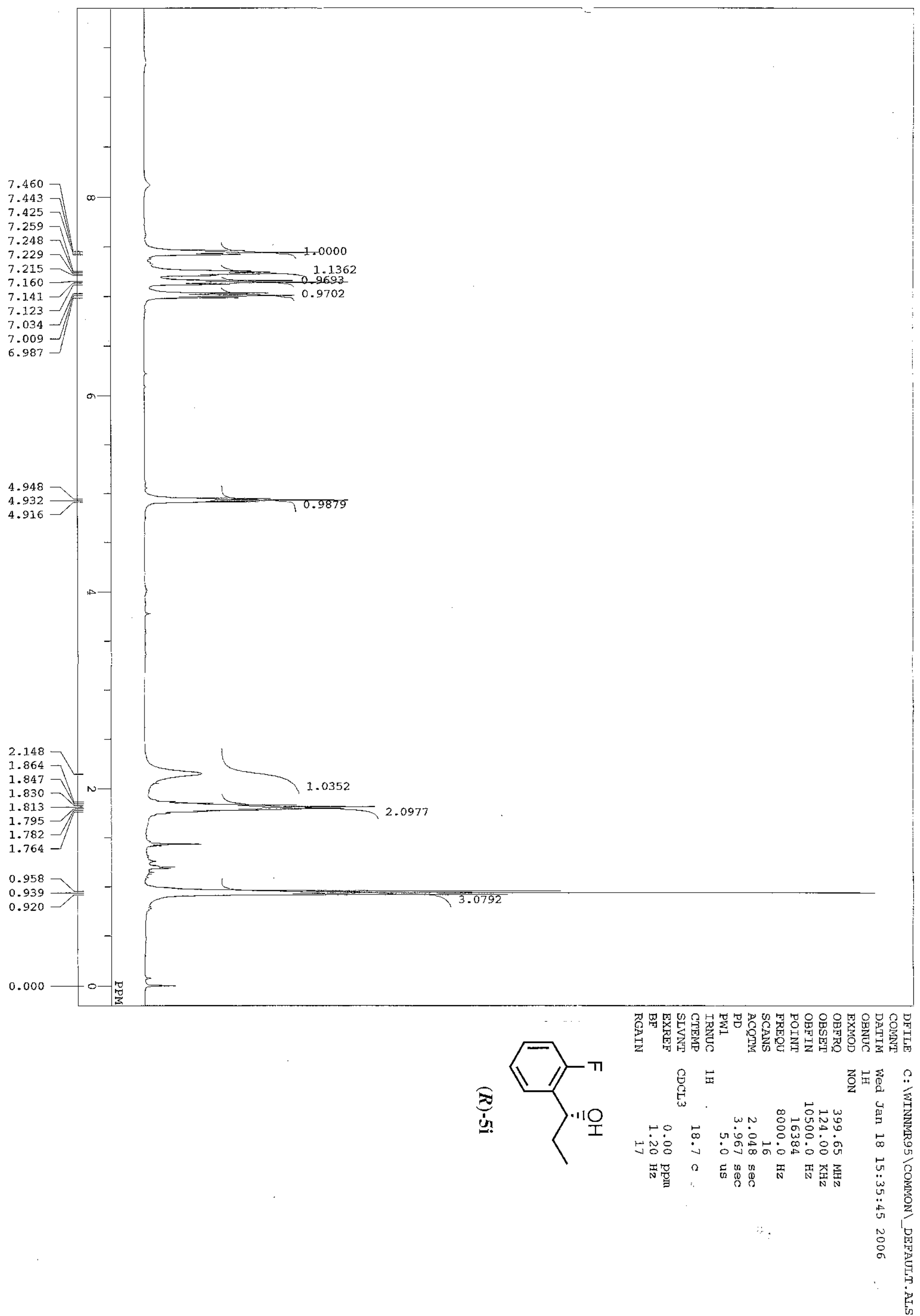


Date: 2006 年 3 月 14 日 (火) 9:34 AM

Data: PARA

Method: 60min

Sampling Int: 0.1 Seconds

Data:

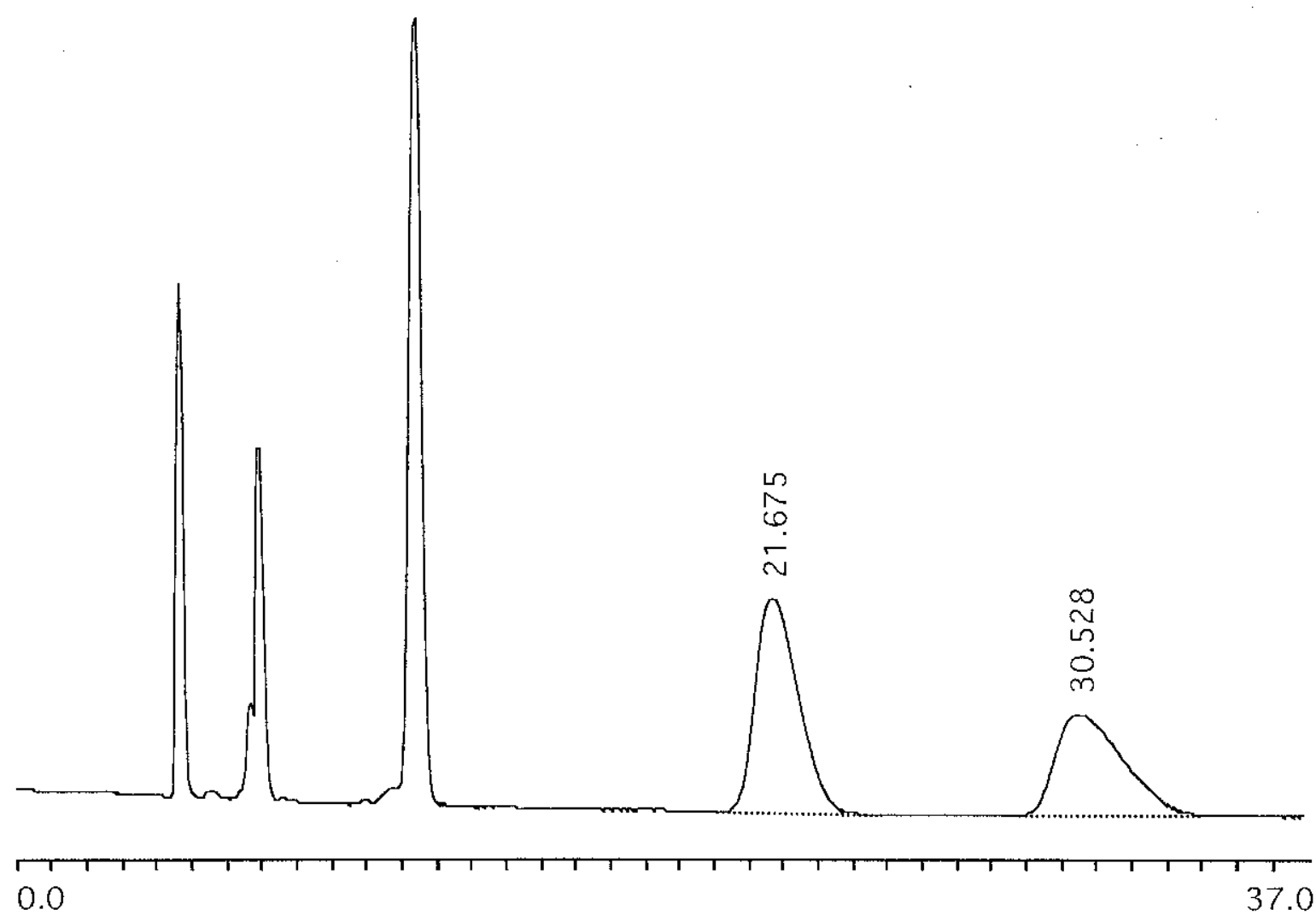

Analysis: Channel A

\begin{tabular}{cccrrr} 
Peak No. & Time & Type & Height $(\hbar V)$ & Area $($ tV-sec $)$ & Area\% \\
1 & 21.675 & ${ }^{N}$ & 10091 & 823940 & 57.189 \\
2 & 30.528 & $* \mathrm{~N}$ & 4822 & 616768 & 42.810 \\
\multicolumn{2}{l}{ Total Area } & & & -1440708 & 99.999
\end{tabular}<smiles>O[C@H](c1ccccc1)c1ccc(F)cc1</smiles>

(S)-3a 


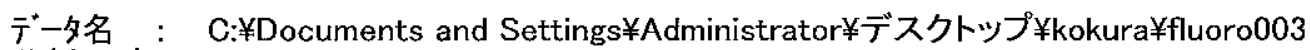

分析日時：2006/01/07 12:03:19

印刷日時：2006/04/19 16:11:14

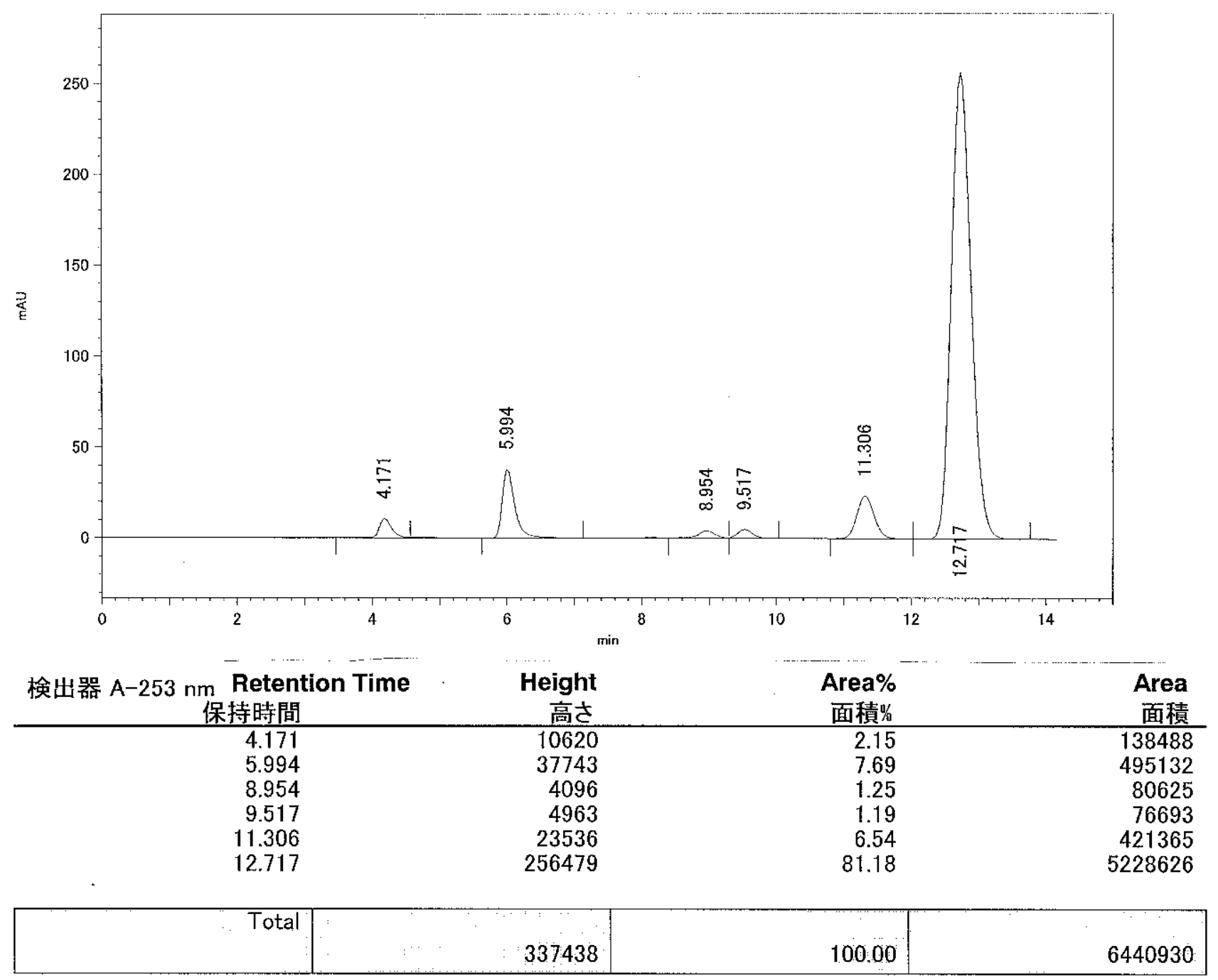<smiles>O[C@H](c1ccccc1)c1ccccc1F</smiles>

(S)-3c

$(S, S)$ cat. was used. 


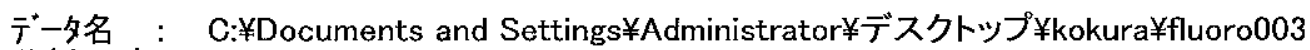

分析日時：2006/01/07 12:03:19

印刷日時：2006/04/19 16:11:14

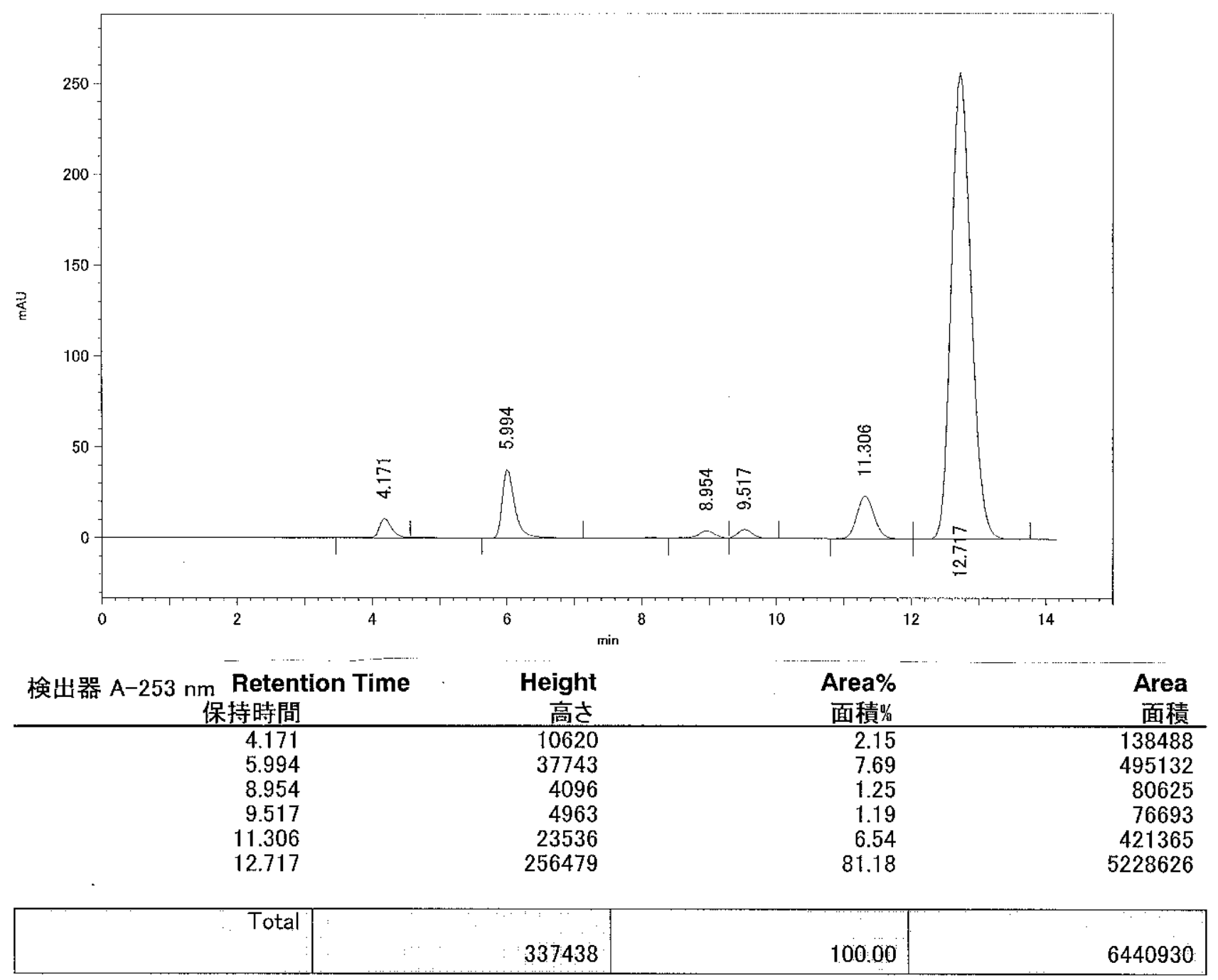<smiles>O[C@H](c1ccccc1)c1ccccc1F</smiles>

(S) $-3 \mathrm{c}$

$(S, S)$ cat. was used. 
データ名 ： G:¥Documents and Settings¥Administrator¥デスクトップ¥S.Tanaka¥Ex7001

分析日時：2006/03/20 17:21:36

印刷日時： 2006/04/19 16:24:37

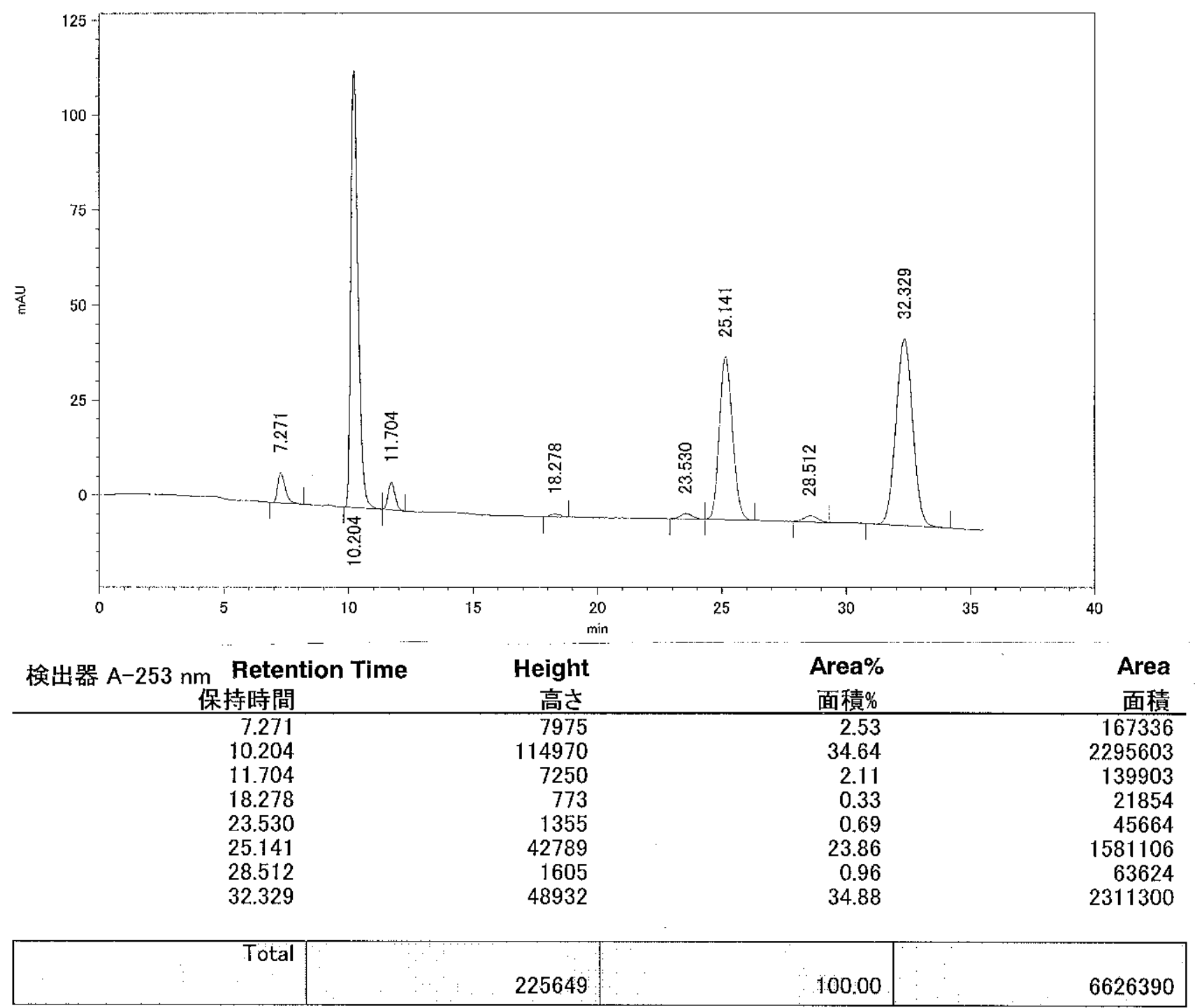<smiles>O[C@H](c1ccccc1)c1ccccc1Br</smiles>

$(S)-3 e$ 
$\overline{\mathrm{T}}^{*}$ 一夕名：C:¥Documents and Settings¥Administrator $¥$

分析日時：2006/03/11 14:06:50

印刷日時：2006/04/19 16:11:58

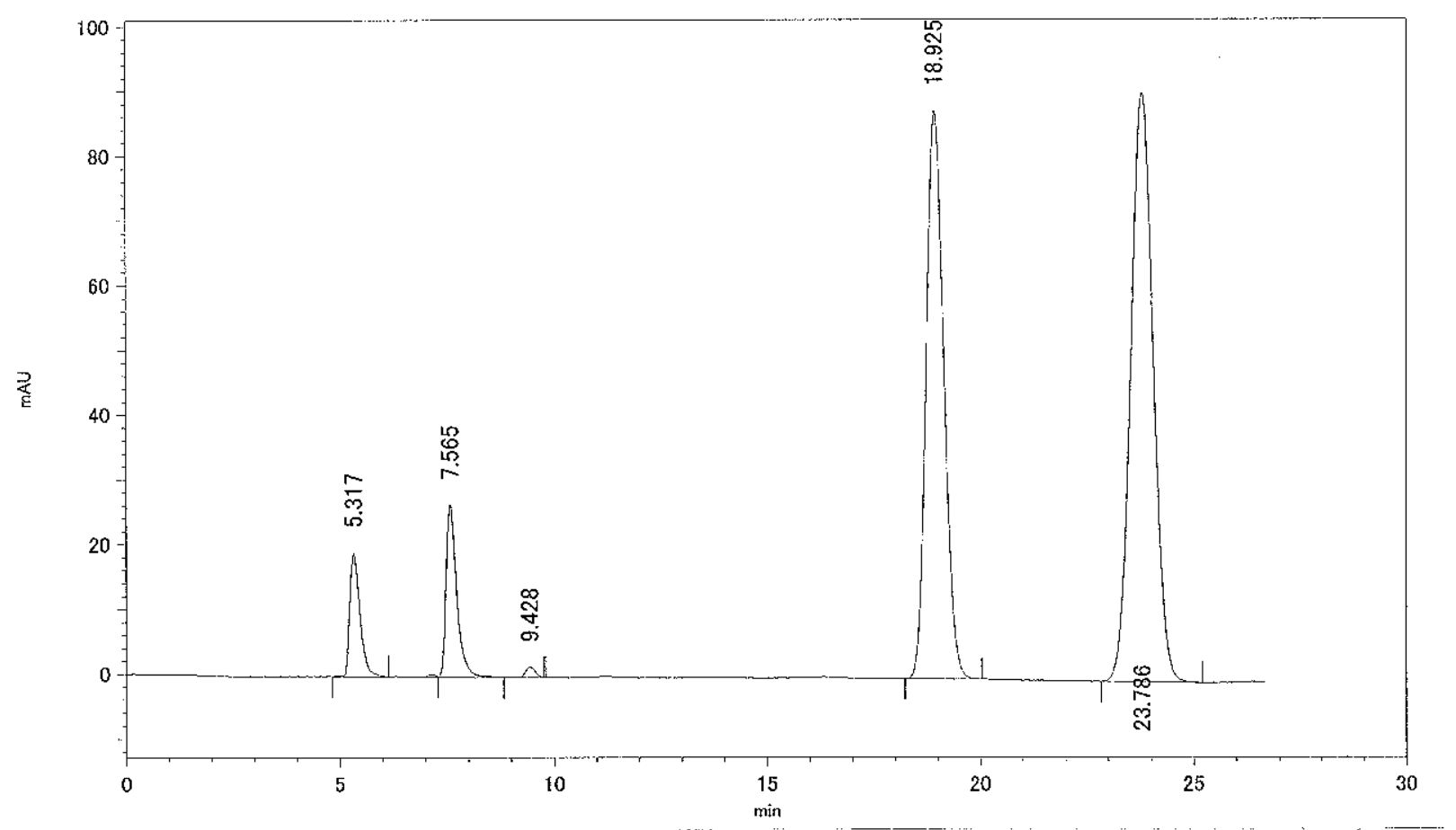

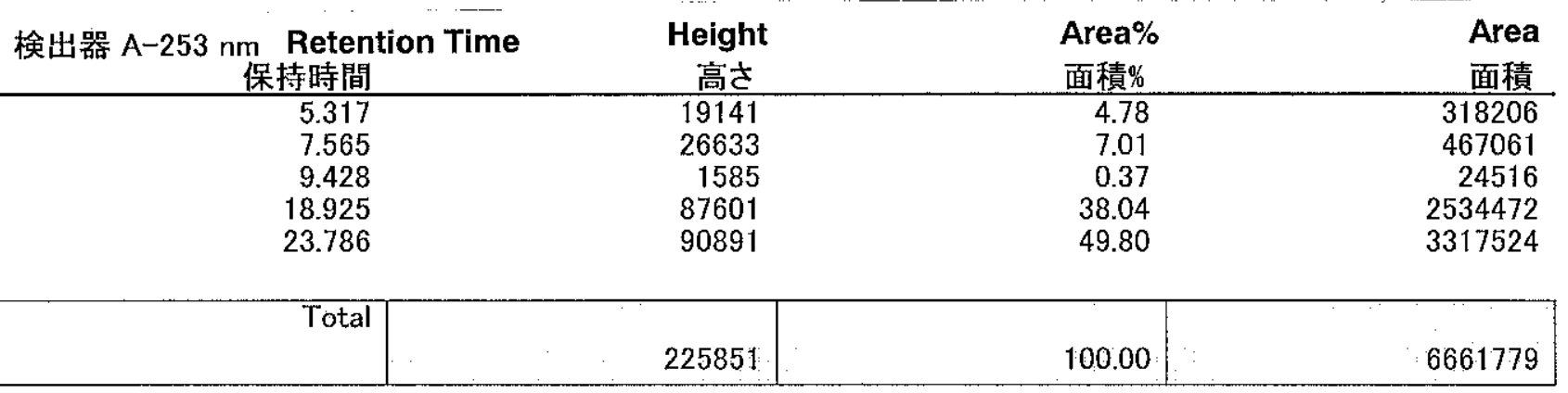<smiles>O[C@H](c1ccccc1)c1ccccc1I</smiles>

(S) $-\mathbf{3 f}$

$(S, S)$ cat. was used. 


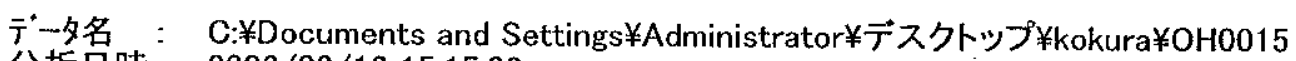
分析日時： $2006 / 03 / 16$ 15:15:32

印刷日時：2006/03/16 15:45:35

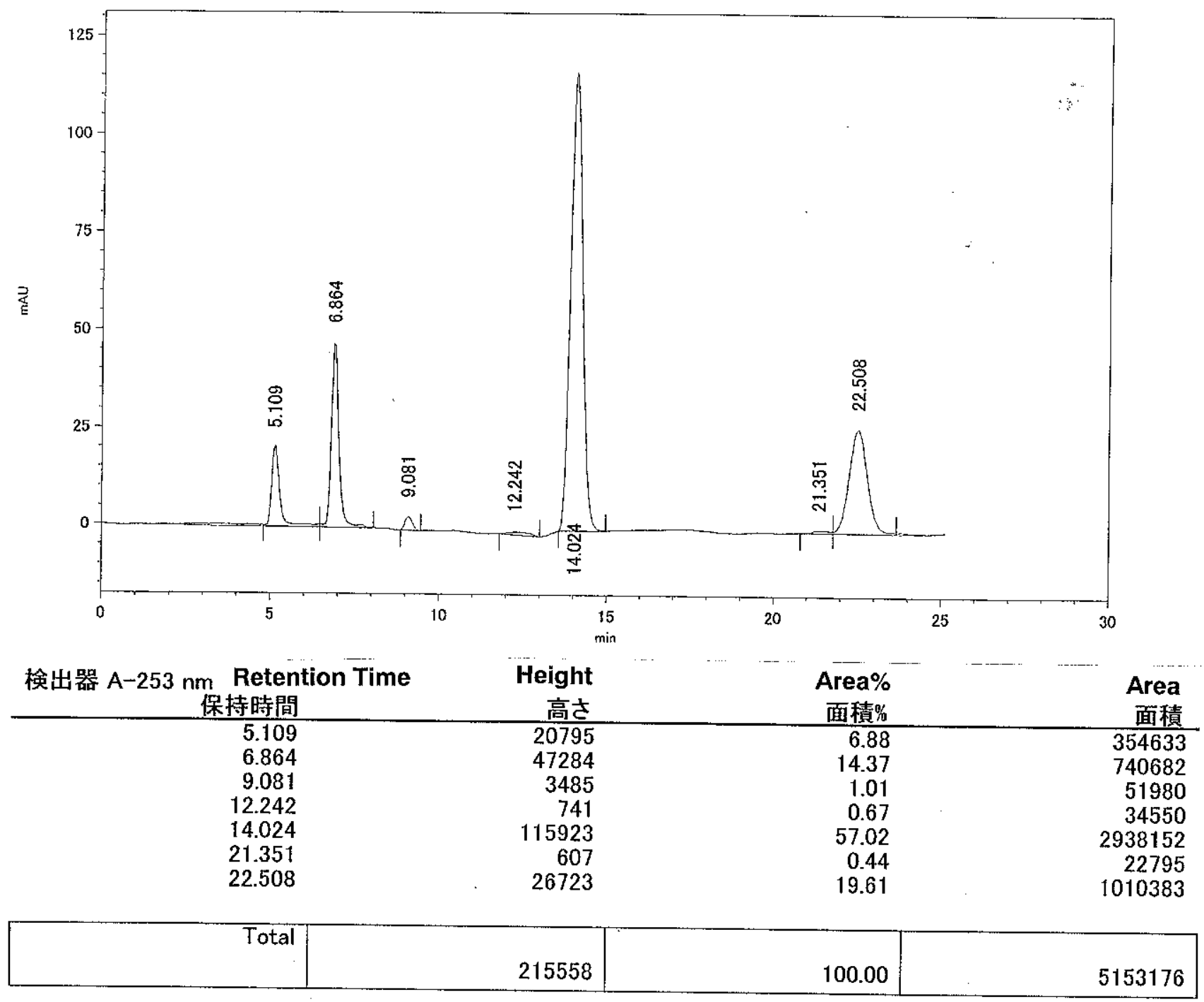<smiles>Oc1ccccc1C(O)c1ccccc1</smiles>

$3 g$ 


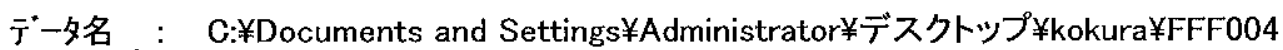

分析日時： $2005 / 10 / 2019: 40: 16$

印刷日時：2006/04/19 18:15:50

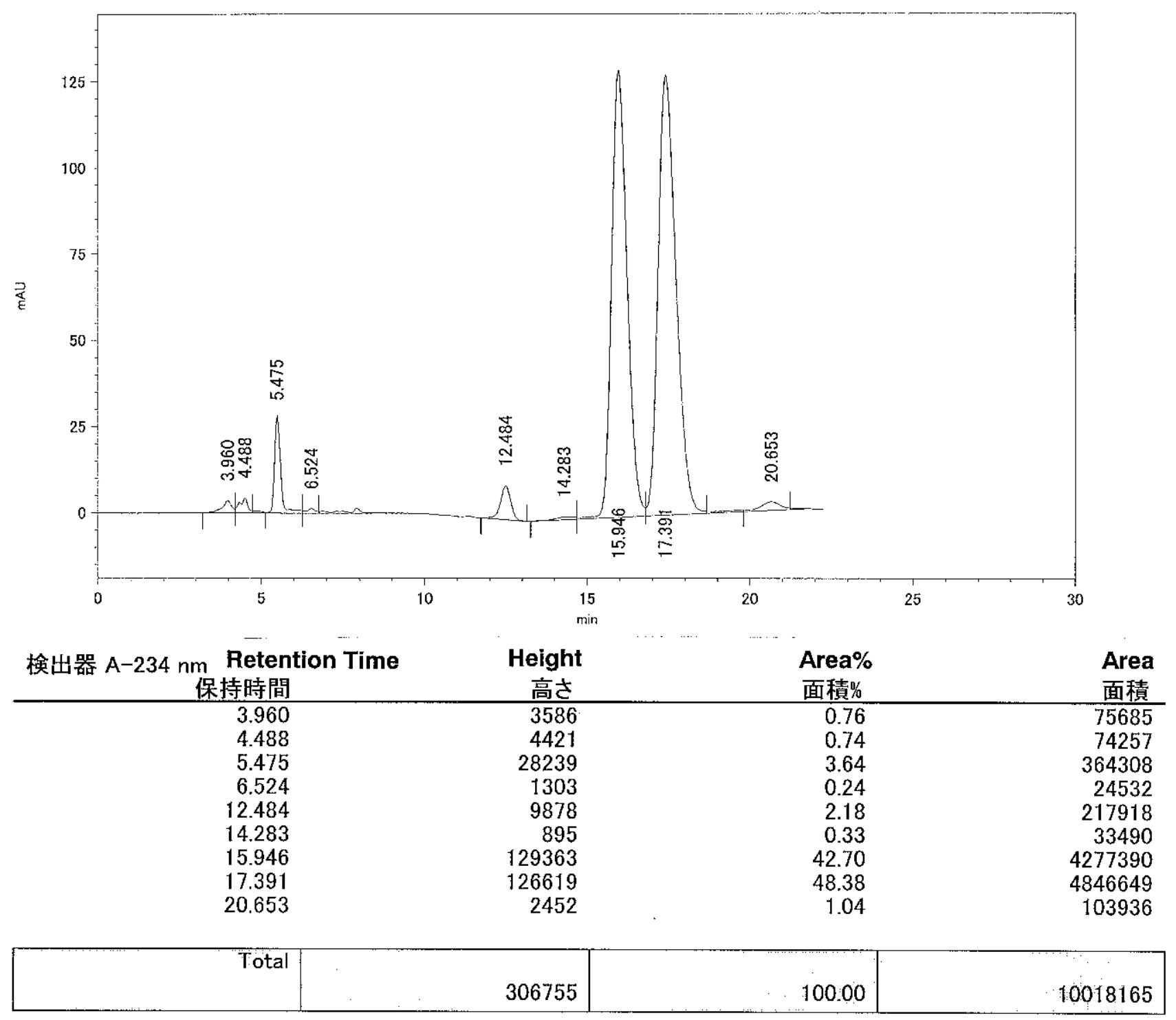

$3 \mathbf{h}$ 
データ名：C:¥Documents and Settings ¥Administrator ¥デスクトップ¥kokura¥benzhydrol010

分析日時：2005/12/17 16:32:09

印刷日時：2006/04/19 16:38:27

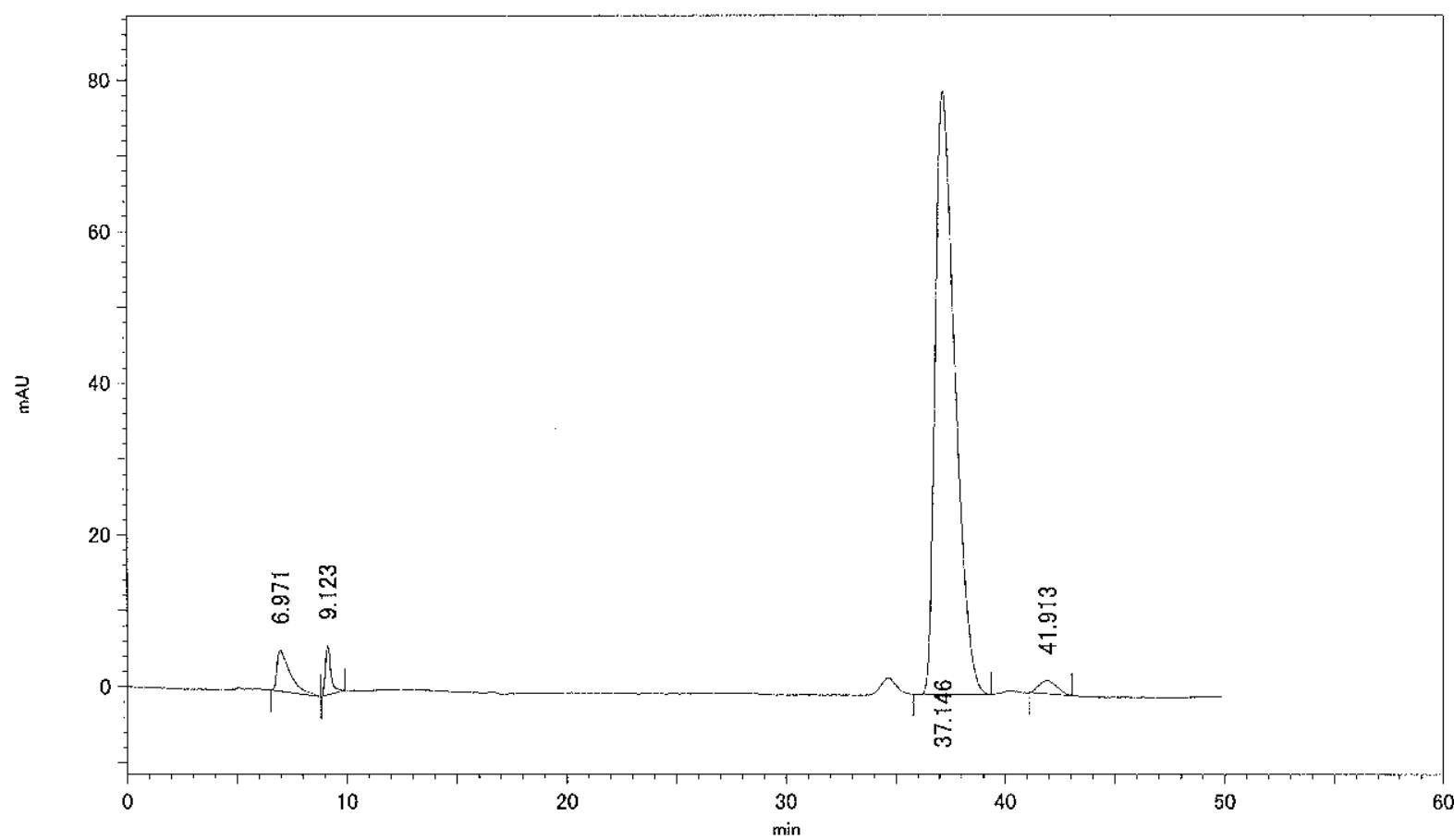

\begin{tabular}{|c|c|c|c|}
\hline $\begin{array}{r}\text { 検出器 A-253 nm Retenti } \\
\text { 保持時間 }\end{array}$ & $\begin{array}{c}\text { Height } \\
\text { 高さ }\end{array}$ & $\begin{array}{l}\text { Area\% } \\
\text { 面積\% }\end{array}$ & $\begin{array}{l}\text { Area } \\
\text { 面積 }\end{array}$ \\
\hline $\begin{array}{r}6.971 \\
9.123 \\
37.146 \\
41.913\end{array}$ & $\begin{array}{r}5342 \\
6450 \\
79483 \\
1779\end{array}$ & $\begin{array}{r}4.11 \\
2.08 \\
91.92 \\
1.89\end{array}$ & $\begin{array}{r}222102 \\
112400 \\
4967083 \\
102107\end{array}$ \\
\hline Total & 93054 & 100.00 & 5403692 \\
\hline
\end{tabular}<smiles>O[C@H](c1ccccc1)c1c(F)c(F)c(F)c(F)c1F</smiles> 


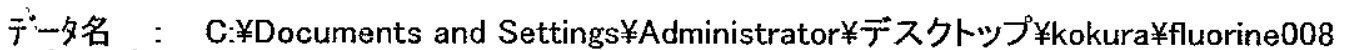

分析日時：2005/11/17 16:41:55

印刷日時：2006/01/25 21:11:10

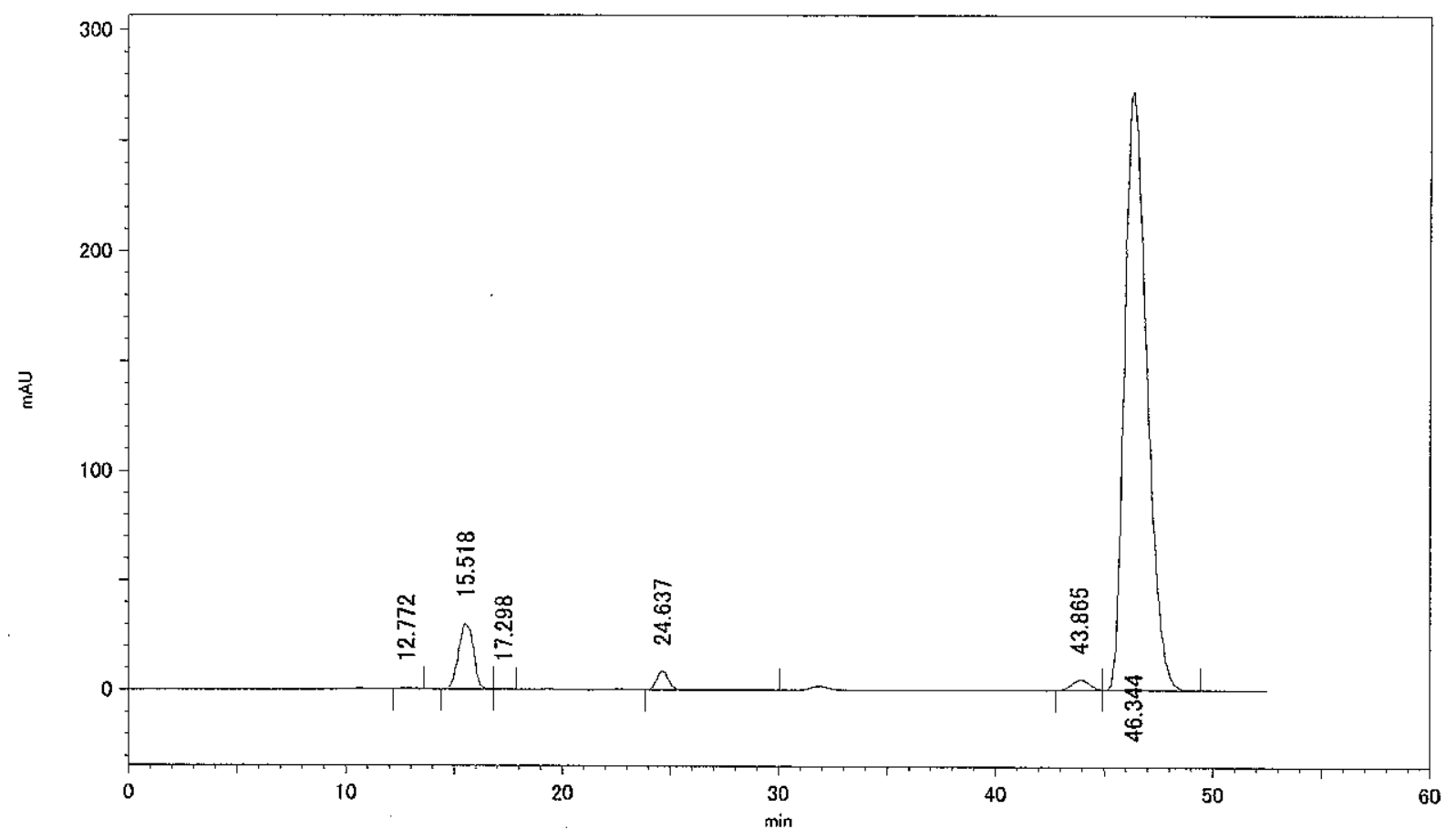

\begin{tabular}{|c|c|c|c|}
\hline $\begin{array}{c}\text { 検出器 A-253 nm Retenti } \\
\text { 保持時間 }\end{array}$ & $\begin{array}{c}\text { Height } \\
\text { 高さ }\end{array}$ & $\begin{array}{l}\text { Area\% } \\
\text { 面積\% }\end{array}$ & $\begin{array}{l}\text { Area } \\
\text { 面積 }\end{array}$ \\
\hline $\begin{array}{l}12.772 \\
15.518 \\
17.298 \\
24.637 \\
43.865 \\
46.344\end{array}$ & $\begin{array}{r}917 \\
29745 \\
703 \\
8468 \\
4660 \\
271694\end{array}$ & $\begin{array}{r}0.20 \\
6.75 \\
0.12 \\
1.52 \\
1.22 \\
90.18\end{array}$ & $\begin{array}{r}42181 \\
1447918 \\
26594 \\
325954 \\
262392 \\
19333397\end{array}$ \\
\hline Total & 316187 & 100.00 & 21438436 \\
\hline
\end{tabular}<smiles>O[C@H](c1ccccc1)c1c(F)cccc1F</smiles>

(R) $\mathbf{- 5 b}$ 
$\overline{\mathrm{T}}^{*}$-夕名 ： C:¥CLASS-VP¥Instrument 1 Preview.dat

分析日時: $2006 / 04 / 1315: 28: 01$

印刷日時：2006/04/13 16:06:06

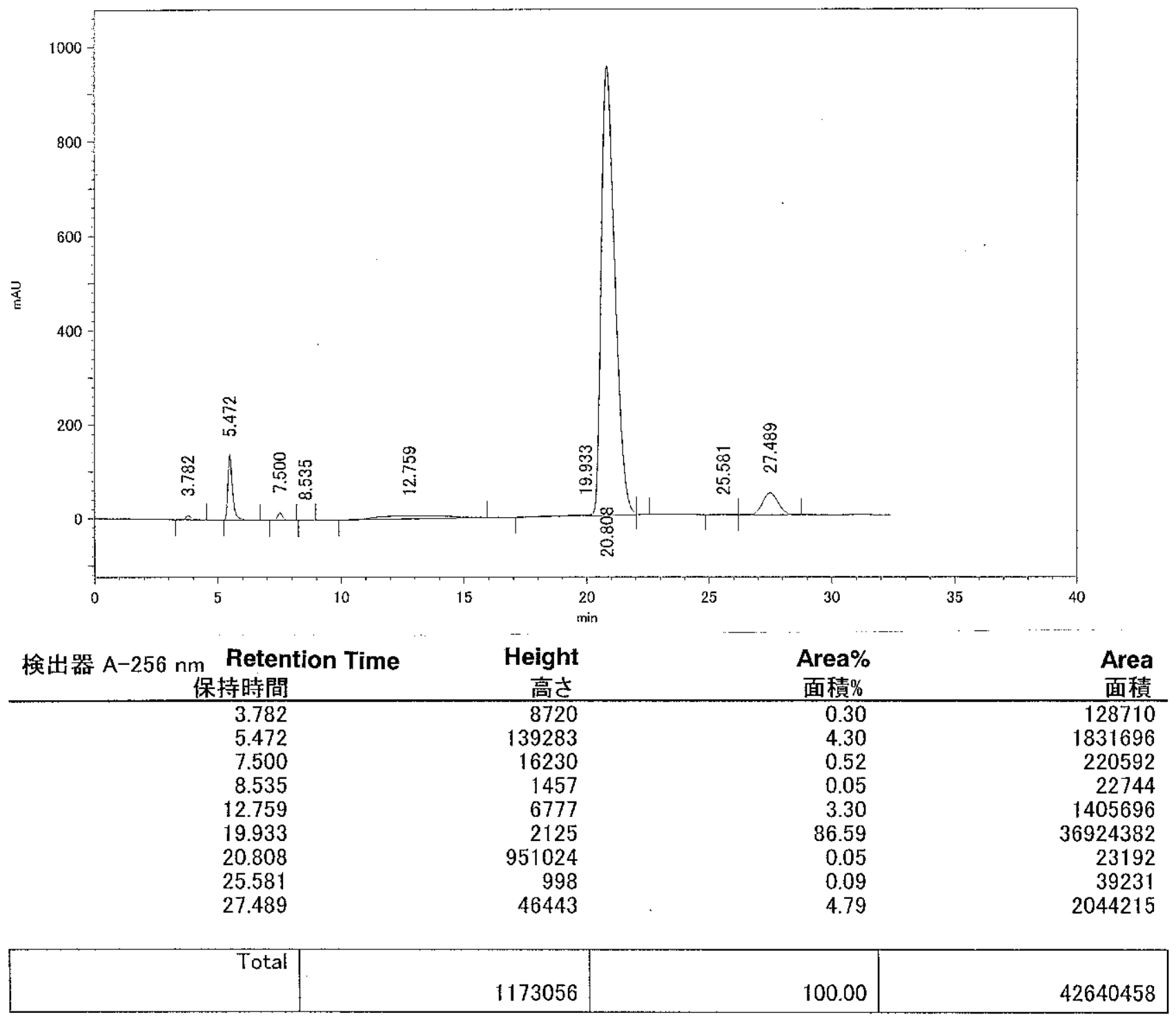<smiles>O[C@H](c1ccc2ccccc2c1)c1ccccc1F</smiles>

(R)-5c

Tentative 
データ名： C:¥Documents and Settings¥Administrator¥デスクトップ¥kokura $¥$ Clbenz007

分析日時： 2006/01/18 16:06:08

印刷日時： 2006/04/19 17:06:11

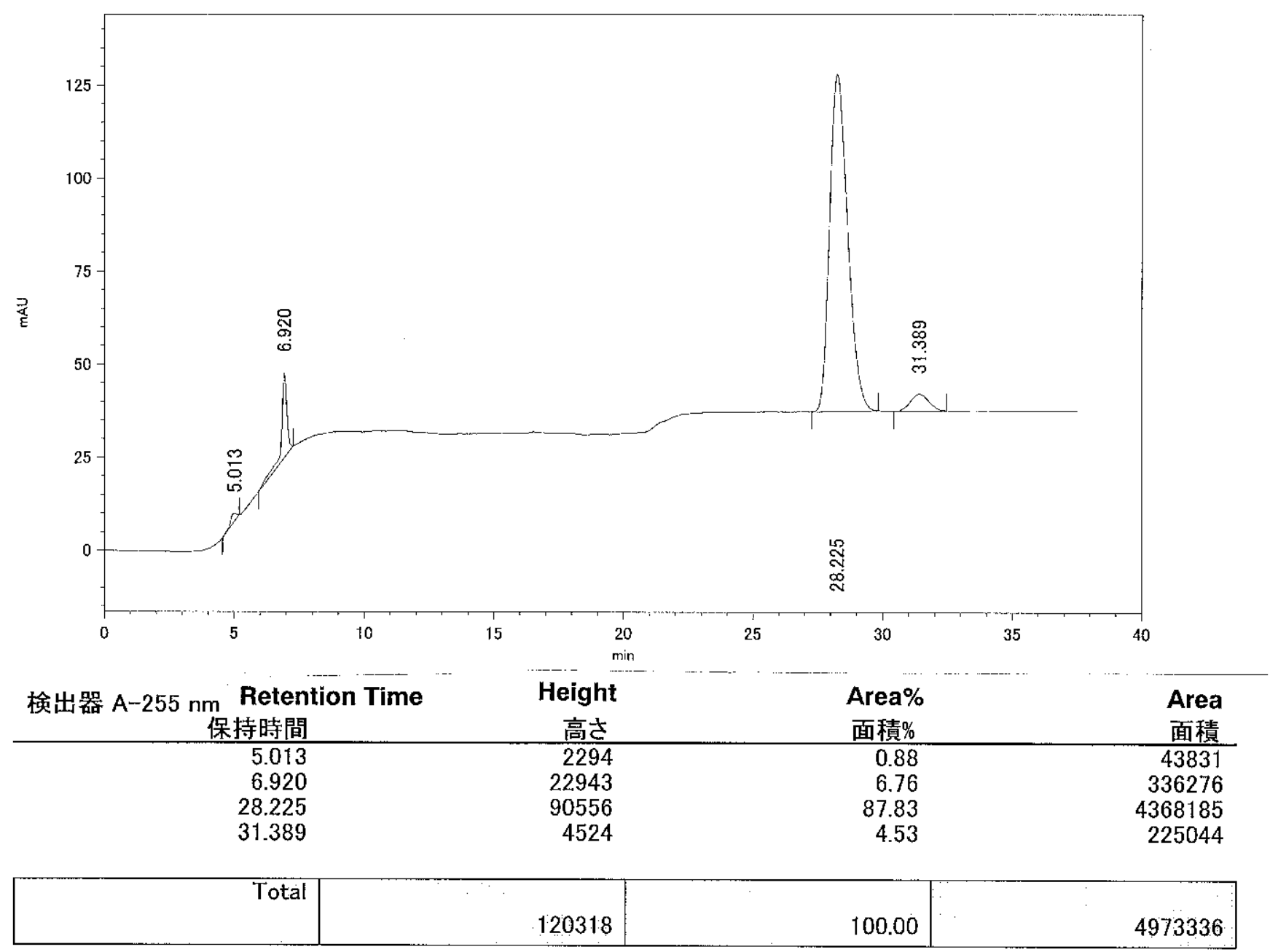<smiles>COc1ccc([C@@H](O)c2ccccc2F)cc1</smiles>

(R) $-5 d$

Tentative 


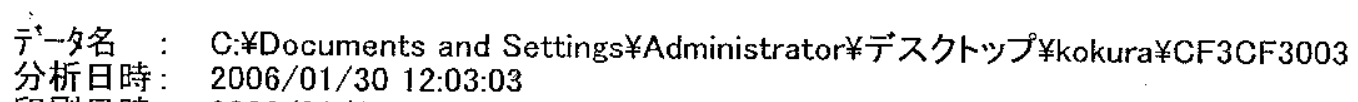

印刷日時： $2006 / 01 / 30$ 12:32:53

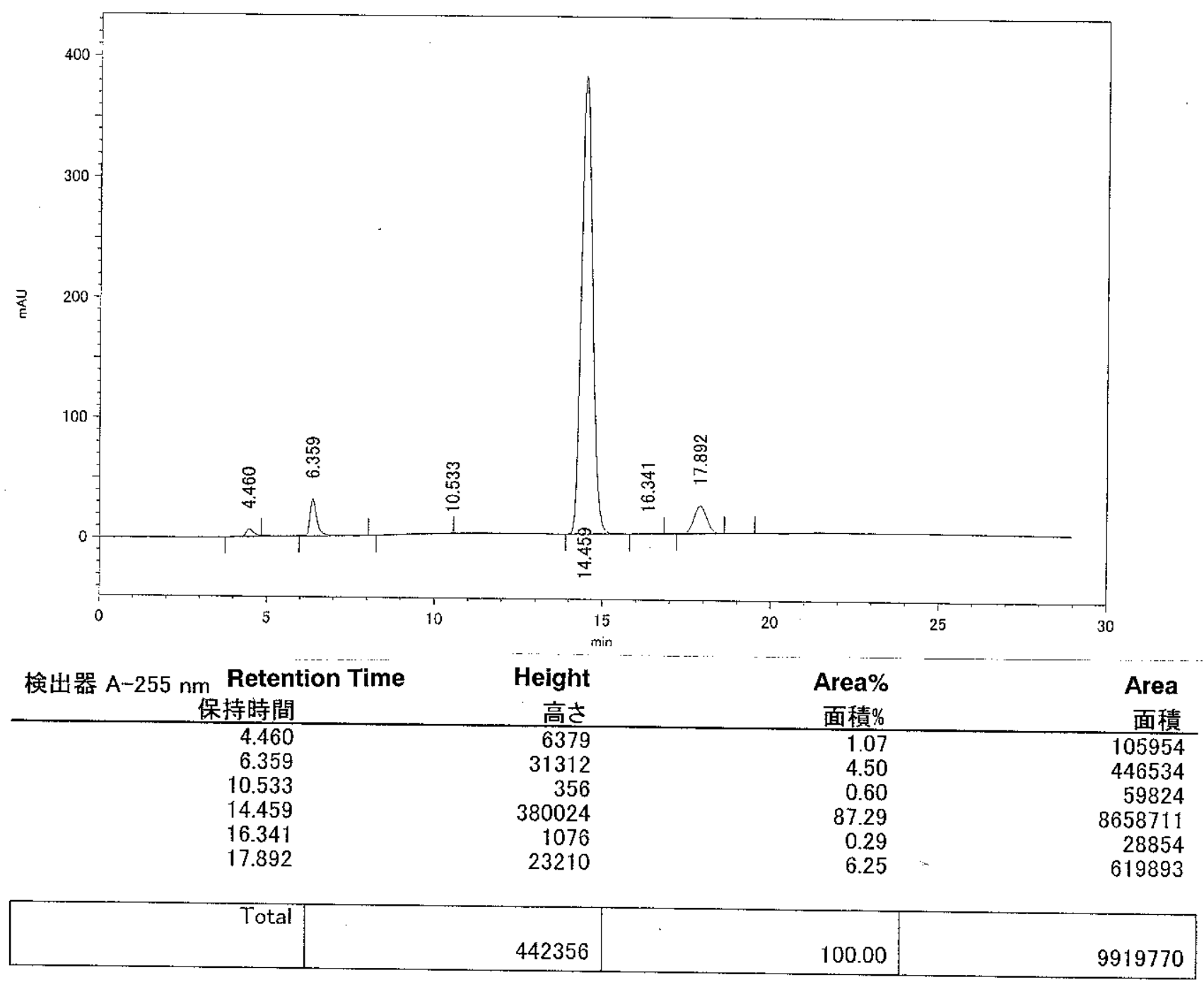<smiles>O[C@H](c1ccc(F)cc1)c1ccccc1F</smiles>

$(R)-5 \mathrm{e}$

Tentative 


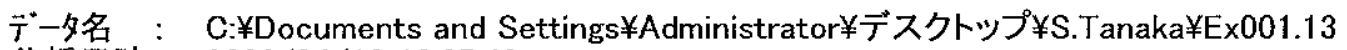

分析日時：2006/04/13 16:07:49，

印刷日時：2006/04/19 17:34:09

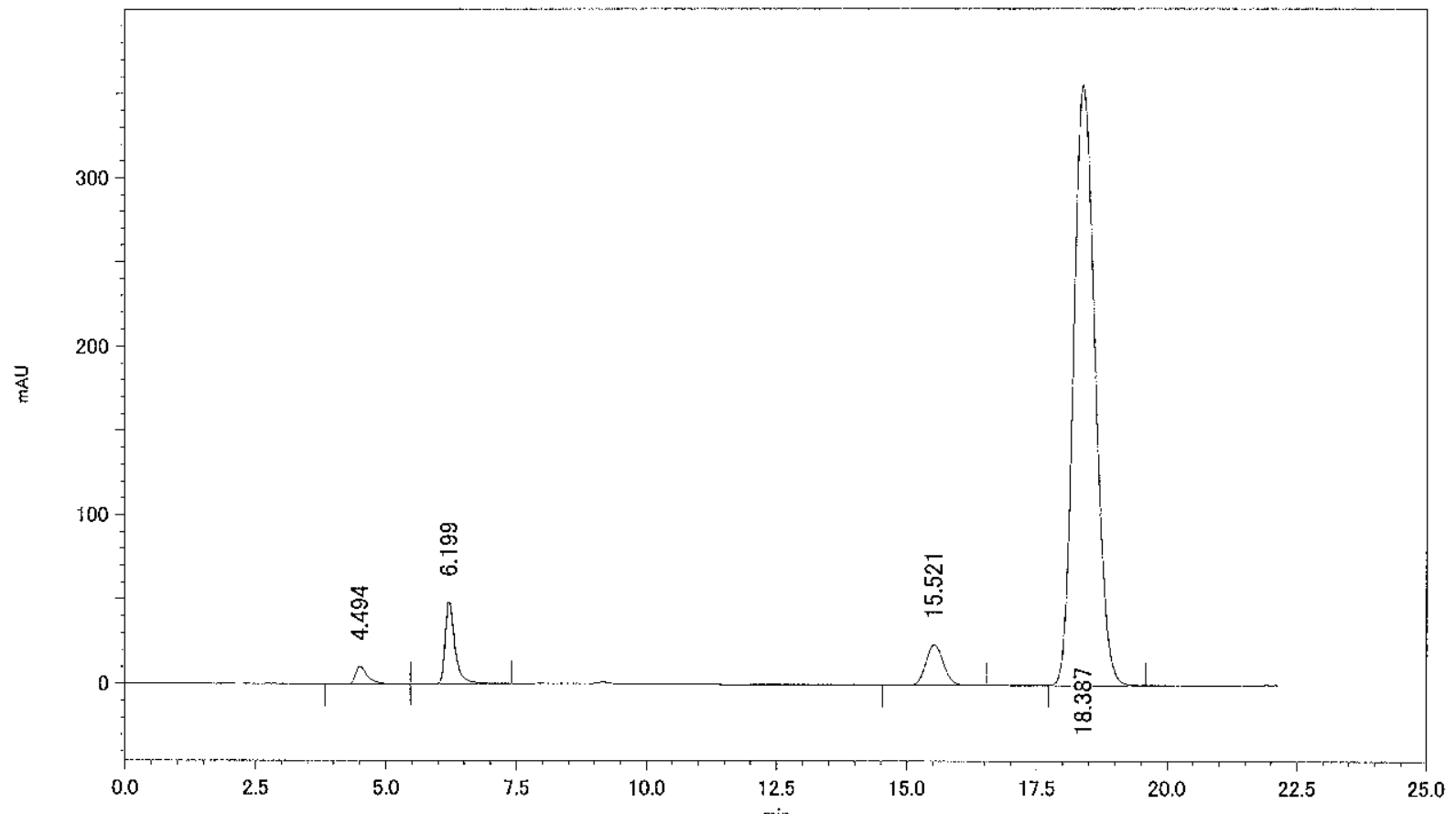

\begin{tabular}{|c|c|c|c|}
\hline $\begin{array}{c}\text { 検出器 A-255 nm Retentio } \\
\text { 保持時間 }\end{array}$ & $\begin{array}{c}\text { Height } \\
\text { 高さ }\end{array}$ & $\begin{array}{c}\text { Area\% } \\
\text { 面積\% }\end{array}$ & $\begin{array}{l}\text { Area } \\
\text { 面積 }\end{array}$ \\
\hline $\begin{array}{r}4.494 \\
6.199 \\
15.521 \\
18.387\end{array}$ & $\begin{array}{r}10368 \\
48043 \\
24045 \\
356241\end{array}$ & $\begin{array}{r}1.42 \\
5.47 \\
4.83 \\
88.28\end{array}$ & $\begin{array}{r}163403 \\
628568 \\
554937 \\
10143160\end{array}$ \\
\hline Total & 438698 & 10000 & 11490067 \\
\hline
\end{tabular}<smiles>COc1ccccc1[C@@H](O)c1ccccc1F</smiles>

(R) $-\mathbf{5 f}$

Tentative 


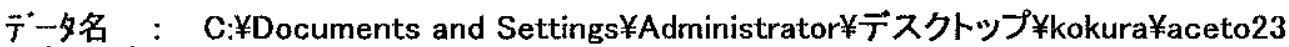

分析日時：2005/12/13 13:59:35

印刷日時：2006/01/25 16:23:04

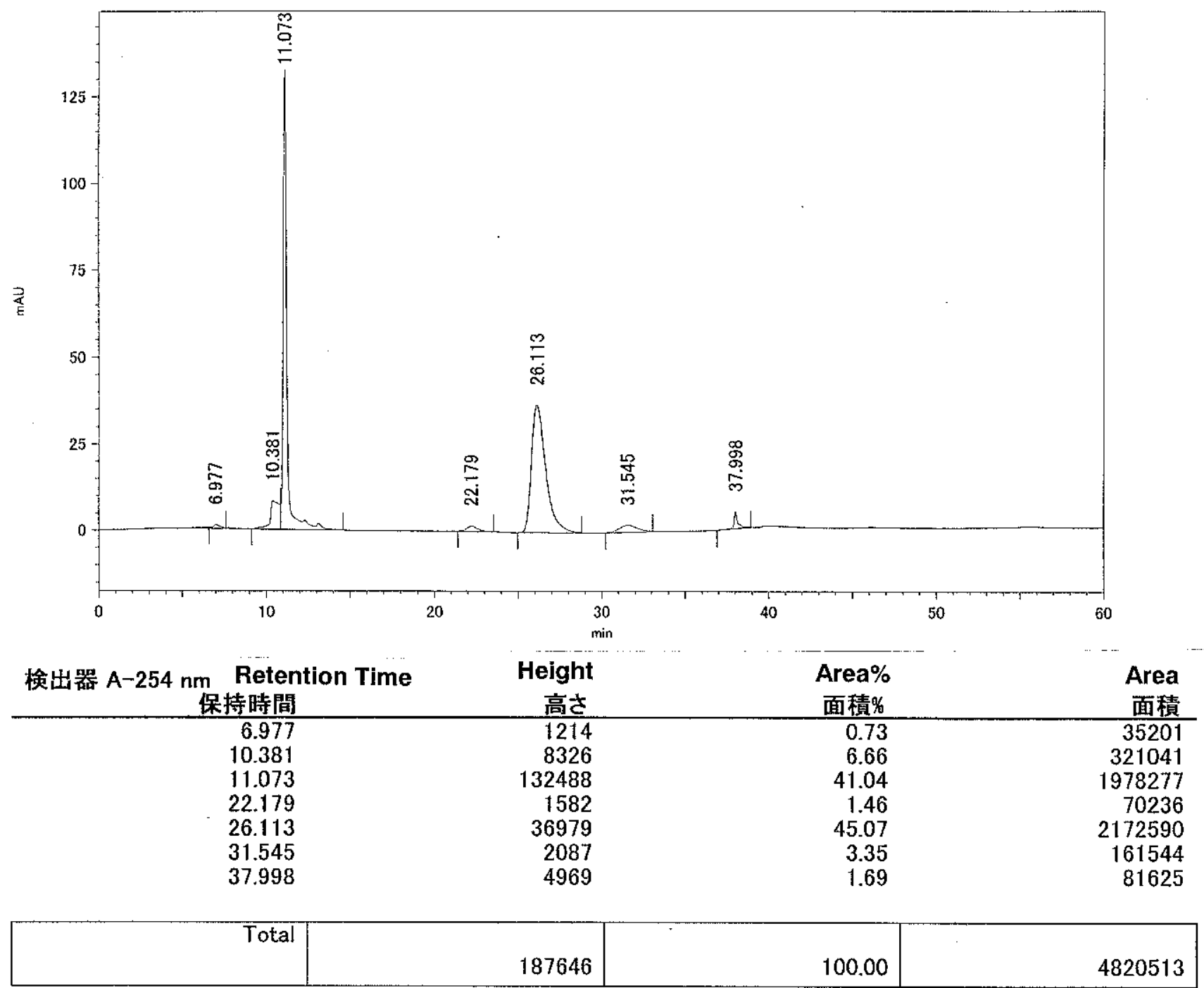<smiles>C[C@H](O)c1ccccc1</smiles>

$(R)-5 g$ 
データ名： C:¥Documents and Settings ¥Administrator ¥デスクトップ¥kokura¥FCH312 分析日時：2006/01/25 14:59:33

印刷日時： 2006/01/25 15:56:18

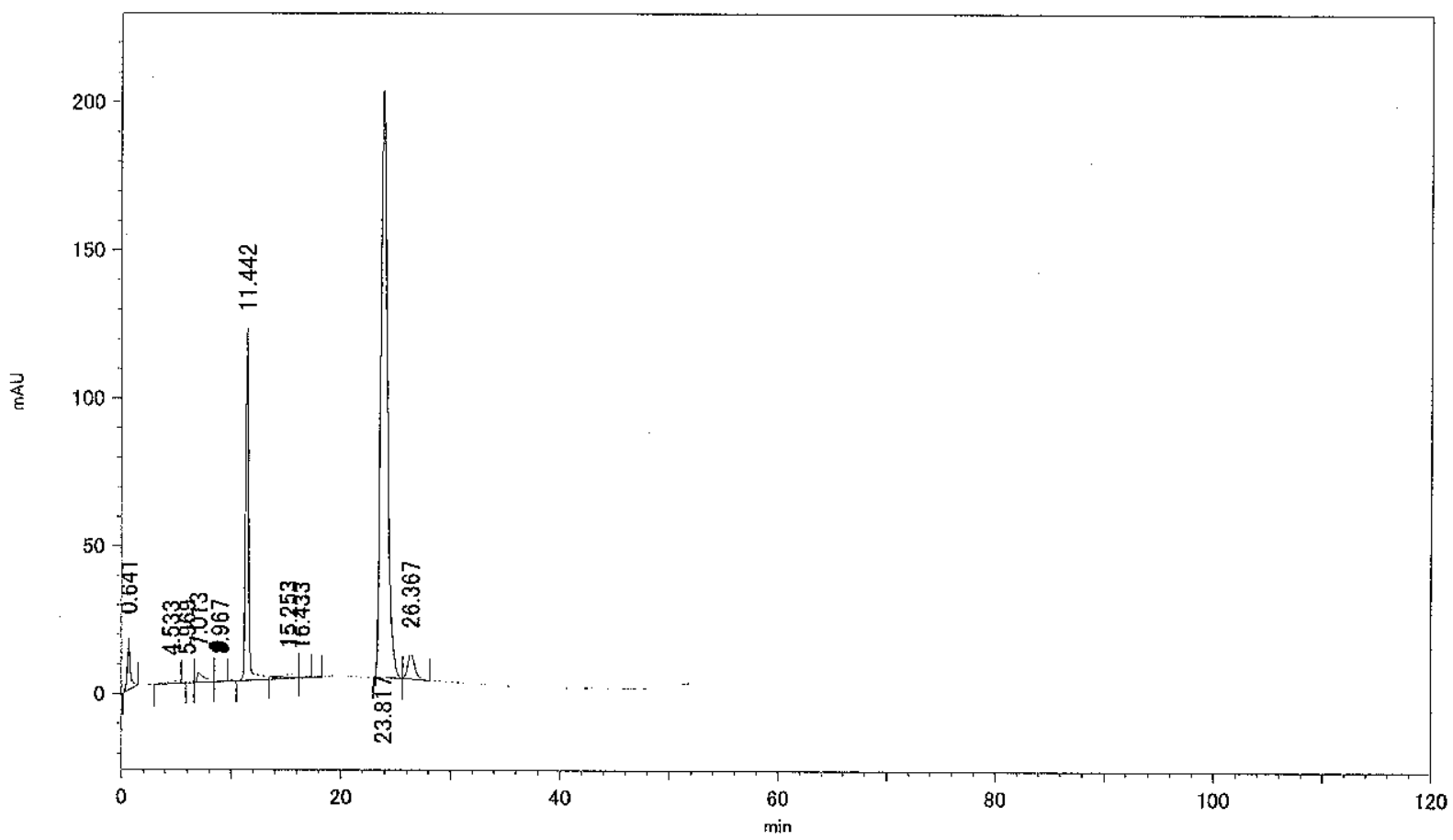

検出器 A-254 nm Retention Time 保持時間

0.641

4.533

5.969

7.013

8.967

11.442

15.253

16.433

23.817

26.367

Height

高さ

Area $\%$

Area

面積\%

面積

2.68

0.63

683

768

3265

0.23

1.38

0.25

20.00

119605

905

0.73

0.24

98712

8376

70.59

27156

159655

28930

2313660

84781

27862

3.26

8167790

377274

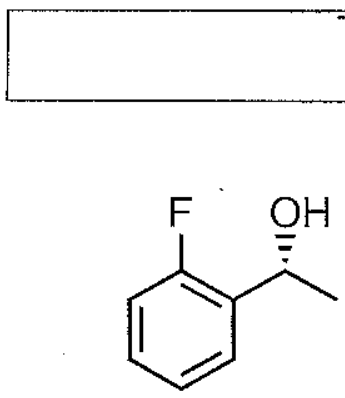

(R) $-5 \mathrm{~h}$ 
デー夕名：C:¥Documents and Settings¥Administrator¥デスクトップ¥kokura¥Clbenz006

分析日時：2006/01/18 12:39:39

印刷日時： 2006/04/19 16:50:33

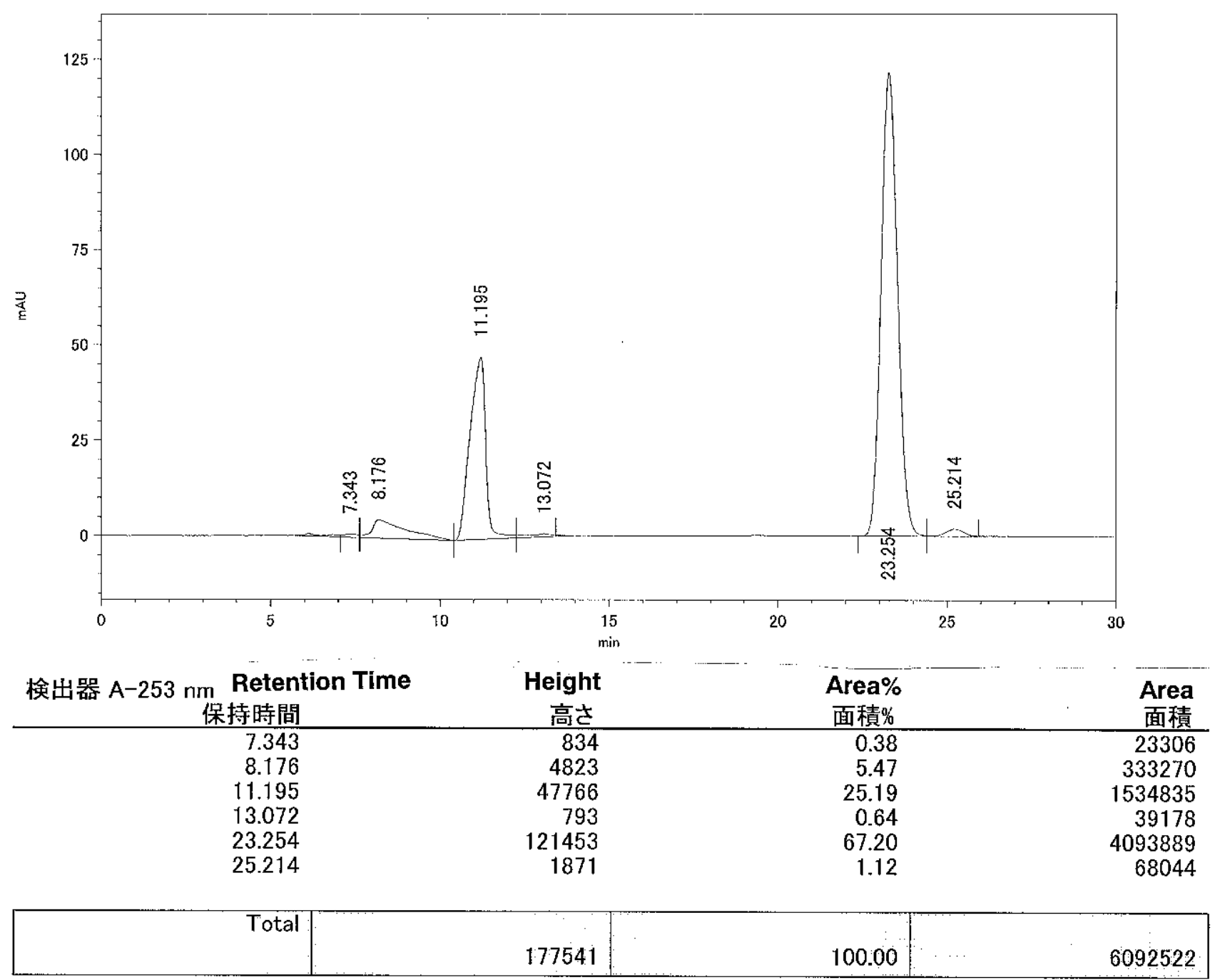<smiles>CC[C@H](O)c1ccccc1F</smiles>

(R)-5i 